\title{
Tax Policy and The Financing of Innovation*
}

\author{
Luis A. Bryce Campodonico (Credit Suisse) \\ Roberto Bonfatti (University of Nottingham) \\ Luigi Pisano (Northwestern University)
}

Sep 302015

Keywords: Innovation, Tax Policy, Asymmetric Information, Adverse Selection

JEL Codes: O38, E60, G38

Published version: doi:10.1016/j.jpubeco.2015.12.010

\begin{abstract}
We study tax policy in a Schumpeterian growth model with asymmetric information in the financing of innovation. Investors cannot a priori distinguish between more or less talented entrepreneurs. Networth allows talented entrepreneurs to self-invest and avoid being pooled with less talented entrepreneurs in the credit market. Increasing networth boosts innovation even when financed through higher profit taxes. Taxing consumption effectively raises net-worth and subsidizes profits simultaneously. Sufficiently taxing consumption implements the social optimum free of adverse selection. If forced to tax consumption less, the government implements a second best allocation with adverse selection when boosting net-worth enough to avoid adverse selection requires taxing profits excessively.
\end{abstract}

${ }^{*}$ Corresponding author: Roberto Bonfatti. Address: School of Economics, University Park, Nottingham NG72RD, United Kingdom. Phone: +44 (0)115 9514297. E-mail: roberto.bonfatti@nottingham.ac.uk. Luis Bryce thanks his colleagues at Northwestern University and the University of Lausanne, in particular Jonathan Parker, for their comments and suggestions. He gratefully acknowledges financial support from the Swiss National Centre of Competence in Research "Financial Valuation and Risk Management" (NCCR FINRISK). Roberto Bonfatti thanks Giammario Impullitti for his comments. 


\section{Introduction}

The private and social gains from technological research diverge in the presence of externalities in the production and dissemination of innovation. The policy prescription of the endogenous growth literature is simple: subsidize innovation activity sufficiently to eliminate that wedge. However, there is substantial evidence that firms face constraints in financing the pursuit, adoption, or acquisition of innovations. ${ }^{1}$ In the presence of asymmetric information, providing incentives to innovators does not necessarily lead to more innovation activity; the government must also take into account the response of financial markets, and prevent the adverse selection problem from constraining innovators.

In our model, some entrepreneurs are more talented than others, but their talent is private information. When the market cannot separate these two types, the demand for credit of untalented entrepreneurs raises the cost of capital of talented entrepreneurs as creditors require compensation for the risk of lending to the untalented. In other words, talented entrepreneurs must pay an adverse selection premium. Indeed, even when the market can separate the two types, the investment decisions of the high types are distorted by their need to avoid being confused with the low types.

To study fiscal policy in this environment, we assume the government can tax labor income, profit, and consumption. Our results about the effects of tax policy reforms on economic growth depend crucially on whether financial markets are in a pooling or separating equilibrium, and the design of optimal policy hinges on which of those equilibria is most conducive to growth when the first best allocation is not implementable.

We show that increasing the after-tax labor income of entrepreneurs is often necessary to increase technological research while at the same time avoiding a pooling equilibrium. The reason is that investable net-worth equals after-tax labor income. With more resources at hand, talented entrepreneurs can pursue more research without facing adverse selection. Thus, boosting net-worth provides a rationale for taxing profits in order to subsidize labor income. In our model, moreover, taxing profits may lead to an overall increase in research,

\footnotetext{
${ }^{1} \boldsymbol{?}$ and $?$ recently reviewed this evidence.
} 
because it may make it easier for high-talent entrepreneurs to differentiate themselves from the low-talent ones. This starkly contrasts the benchmark Schumpeterian growth model, wherein taxing profits could only result in a decrease in research. Nonetheless, substituting labor income taxes with profit taxes is not wholly effective, because eventually entrepreneurs become unconstrained by their relatively high net-worth and poor incentives. At that point, the benchmark and our asymmetric information model behave identically, and further increases in the profit tax are growth-reducing. In other words, there is an inverted-U relationship between after-tax profit and innovation. ${ }^{2}$

Substituting labor income and profit taxes for consumption taxes, i.e. fundamental tax reform, more decidedly boosts technological research. Consumption taxes do not hurt the incentive to innovate, as profit taxes do, nor do they constrain the entrepreneur's effort choice, as labor income taxes do. In fact, when the government can freely tax consumption, it is able to implement the first best level of technological research. Otherwise, the government must tax profit and labor income more and implement a second best equilibrium at a lower level of research.

Surprisingly, if the government is unable to tax consumption sufficiently, ${ }^{3}$ the second best equilibrium exhibits adverse selection. This happens because implementing a separating equilibrium requires a low tax on labor income, which given a low tax on consumption requires an excessively high tax on profits to balance the government's budget.

Our paper is related to several strands of literature. The financial development and economic growth literature (reviewed by ?), has incorporated financial frictions into endogenous growth models to understand, on the one hand,

\footnotetext{
${ }^{2}$ Incidentally, this provides an entirely different explanation for the inverted-U relationship between competition and innovation found empirically by ?.

${ }^{3}$ There are important reasons to consider the effect of limits on consumption taxation. With some exceptions, governments in middle to high income countries do not rely heavily on consumption taxation. On average, taxes on goods and services make up only a third of total tax revenues in OECD countries. Despite the emergence of a large literature arguing in favor of fundamental tax reform, in some countries proposals to tilt the tax base towards consumption have faced serious political difficulties. In Japan, the protracted and conflicted efforts of several political parties to establish and raise consumption taxes provide a good example.
} 
how the frictions affect economic growth and welfare, and on the other hand, how financial institutions reduce these imperfections by providing risk-sharing, screening, and monitoring services. For example, ? incorporate asymmetric information about entrepreneurial quality into a Schumpeterian growth model. However, they preclude adverse selection by introducing financial intermediaries that pay a fee to screen entrepreneurs. The policy focus of this literature has been to estimate the effects of government policies that induce financial institutions to provide more of their services, and how these policies can have long-lasting effects as they allow the economy to develop. Instead, we ask how well the government can pursue policy despite the persistence of financial frictions.

This is the first paper to consider the effect of adverse selection on tax policy in a model of growth. ? develops a model of endogenous growth with adverse selection to measure the negative impact of adverse selection on economic growth, but does not consider policy. However, there are studies of the impact of other financial frictions on growth policy. ? assume entrepreneurs that pursue capital accumulation projects face a moral hazard problem: outside creditors are unable to claim more than the entrepreneur's wealth at the time the project is completed as payment. Taxing profits of rich entrepreneurs to subsidize the net-worth of poor entrepreneurs increases growth because the disincentive effect of the profit tax to the rich is secondary to the benefit of alleviating the financial constraints of the poor. To contrast, our paper rationalizes a policy of taxing profits to subside net-worth without relying on a financial constraint that heterogeneously affects entrepreneurs. ? show that when risk-averse entrepreneurs face an un-diversifiable income stream stemming from their research, unconditional transfers to entrepreneurs raise the incentive to pursue research by lowering the marginal utility cost of failure. However, if entrepreneurs were able to insure against their income risk, unconditional transfers would have no effect on research effort. Instead, in our model an unconditional transfer would boost research effort even if entrepreneurs were risk-averse and able to insure against income risk as long as adverse selection constrained the entrepreneur's effort. 
The paper is structured as follows. Section 2 describes the setup and analyzes the case of perfect information. Section 3 develops the model of asymmetric information, and analyzes the effects of small changes in policy. Section 4 studies the optimal policy problem, and Section 5 concludes. Furthermore, Appendix A completes the description of the model of section 2, while Appendix B provides proofs to the lemmas and propositions within the paper.

\section{A Benchmark Model of Schumpeterian Growth}

The basic structure of the economy imperfectly follows chapter 4.3 in ?. In this section we intend only to explain the key ingredients of the innovation process necessary to develop and understand the results of this paper. For a complete description of the benchmark model, refer to Appendix A. Throughout the paper, we only consider equilibria with a risk-free interest rate equal to zero $(r=0)$ to simplify the analysis.

There are three types of tradable goods: consumption, a unit continuum of intermediate products, and a unit continuum of industry-specific labor inputs. The intermediate and consumption goods perish each period. There are two types of agents, entrepreneurs and consumers. All agents are completely informed about the model, themselves, and each other. Each agent lives two periods, is able to provide a unit of industry-specific labor effort in his first period of life, and maximizes expected consumption. While any agent can start a business investing in, and producing, existing intermediate goods, only entrepreneurs are capable of pursuing technological research innovating on existing intermediate goods. 


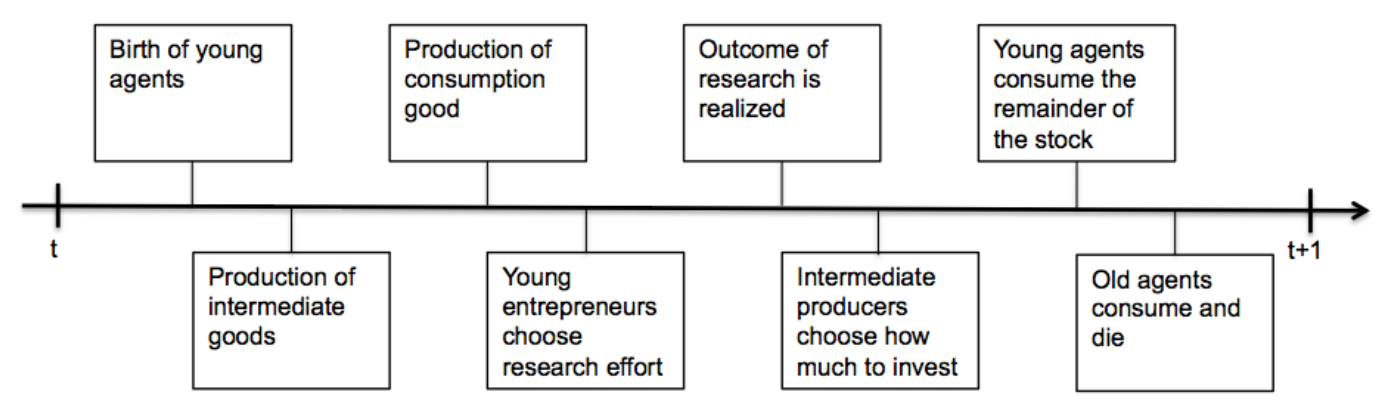

Figure 2.1: Benchmark Model Timeline

At the beginning of period $t$, in each industry one entrepreneur and $L-1$ consumers are born. Also present are one entrepreneur and $L-1$ consumers born in period $t-1$. Each industry is monopolized by a single producer, who owns the blueprint of the technologically-superior intermediate good. When the industry innovated in period $t-1$, the monopoly is held by the old entrepreneur, otherwise it is held by a random old consumer who inherited the blueprint from the previous owner. ${ }^{4}$

A perfectly competitive sector produces the consumption good, employing the entire spectrum of industry-specific labor and intermediate goods. From the consumption good producers, the young agents receive a wage and the intermediate good producers receive payments for their goods. In turn, old agents who invested at $t-1$ in the intermediate good producers receive the return on their investment.

At this point in the timeline, the only good trading in the economy is the consumption good. Young agents may either consume their entire net wage, or lend to young entrepreneurs investing in research or to young consumers investing in production of intermediate goods for period $t+1$. In sequence, young entrepreneurs choose how much of the consumption good to invest in research, and how much of it to contribute in equity as opposed to external financing. Afterward, the outcome of research is revealed. Also, the technologically superior producer (and monopolist) at $t$ passes on his blueprint to a

\footnotetext{
${ }^{4}$ Think of this consumer as the descendant of the last entrepreneur to innovate; he lacks entrepreneurial talent and behaves as a consumer.
} 
young consumer. Then, the technologically superior producer at $t+1$ will either be the young entrepreneur at $t$ if he innovated or the young consumer who inherited the best technology at $t$. The young entrepreneurs and consumers now decide how much of the consumption good to invest in production of the intermediate good, while the old consume and die. The young consume the remainder of the stock not invested in research or intermediate good production. Period $t$ ends, and period $t+1$ begins with the birth of a new generation of agents.

Uniformly throughout the model, industry variables are denoted by a capital Roman letter with an index $i$, e.g. $X_{i}$. Industry variables adjusted by industry frontier productivity $A_{i}$ are denoted by the lower case, e.g. $x_{i} \equiv \frac{X_{i}}{A_{i}}$. Aggregate (or average) variables drop the index, e.g. $X \equiv \int_{0}^{1} X_{i} d i$, and these variables adjusted for average productivity are denoted by the lower case without the index, e.g. $x \equiv \frac{X}{A}$.

\subsection{The Set of Policy Instruments}

Suppose the government employs a time-invariant set of tax schedules on labor, consumption, and profit. We assume taxes take the form of quantity-invariant proportional rates, so that tax burdens vary linearly with agents' choices and the analysis remains tractable. Notably, we do not allow for taxes on capital gains, production, or investment. Including a larger set of taxes would distract the reader from the main points of this paper, without enough additional insights. $^{5}$

We assume all agents are taxed at equivalent rates and denote the set of tax rates by $\tau$. An element of the set receives a subscript representative of the item it taxes: $w$ for labor income, $\pi$ for profit, and $c$ for consumption. More concisely, $\tau=\left(\begin{array}{lll}\tau_{\pi} & \tau_{w} & \tau_{c}\end{array}\right)^{\prime}$. The government cannot require a payment

\footnotetext{
${ }^{5} \mathrm{~A}$ capital gains tax is similar to a profit tax; they both reduce an entrepreneur's incentive to pursue research. Production taxes, by manipulating the revenue and cost of producing intermediate goods, would be able to rectify the appropriability problem caused by monopoly power, a well known result that does not interact in an interesting way with the messages of the paper. A tax on investment, like a profit tax, reduces the incentive to pursue research, but it also discourages production of intermediates thus unnecessarily complicating the analysis.
} 
higher than the labor income or profit being taxed, i.e. $\tau_{w}, \tau_{\pi}, \in(-\infty, 1]$. Additionally, if the tax rates were so generous as to imply a zero or negative price of consumption the agents would choose to consume unboundedly, so in order for an equilibrium to exist it must be that $\tau_{c} \in(-1, \infty)$.

The equilibrium concept for the game between the government and the agents is a static Nash Equilibrium with a first-mover advantage for the government. The government first submits a time-invariant schedule of tax rates $\tau$. Second, the agents choose their best responses to the government's tax plan.

\subsection{Research and Innovation}

Entrepreneurs can be of two types, high talent $(H)$ and low talent $(L)$. The entrepreneur's type is independently drawn in each industry and period. With

probability $\frac{1}{2}$ the entrepreneur born in industry $i$ at time $t$ is a high type, with probability $\frac{1}{2}$ he is a low type.

If the young entrepreneur of type $J \in\{H, L\}$ commits $Z_{i t}$ consumption goods to research, the technology of industry $i$ at $t+1$ obeys

$$
A_{i, t+1}=\left\{\begin{array}{ll}
\gamma A_{i t} & \text { with prob. } a_{J} \mu\left(\frac{Z_{i t}}{A_{i t}}\right) \\
A_{i t} & \text { with prob. } 1-a_{J} \mu\left(\frac{Z_{i t}}{A_{i t}}\right)
\end{array},\right.
$$

where $\mu\left(\frac{Z_{i t}}{A_{i t}}\right)$ is an increasing concave function of its argument, $\mu(0)=0$, $a_{H} \mu(\infty) \leq 1, a_{H}>a_{L}>0$, and $\gamma>1$. Technology $A_{i t}$ corresponds to the productivity with which workers born into industry $i$ at time $t$ produce consumption goods. More formally, given inputs of $L$ labor-units and $X_{i t}$ intermediate goods per industry, the resulting consumption good output $Y_{t}$ is given by

$$
Y_{t} \equiv \int_{0}^{1}\left(A_{i t} L\right)^{1-\alpha} X_{i t}^{\alpha} d i, \quad 0<\alpha<1
$$

innovations thus raise the demand for intermediate goods.

If the entrepreneur innovates, he becomes the intermediate good monopolist and earns profits. Otherwise, he earns nothing. An intermediate good 
monopolist earns profits

$$
\Pi_{i, t+1}=(1-\alpha) \alpha^{\frac{1+\alpha}{1-\alpha}} A_{i, t+1} L
$$

in period $t+1$, by investing consumption goods in period $t$, and later selling intermediate goods to competitive consumption good producers at a markedup price.

Young entrepreneurs can finance their research by contributing equity, or by borrowing from other young agents. If they borrow, entrepreneurs only repay their debt when the project is successful. Because investment in research is risky, it must pay an interest rate higher than the risk-free rate $r=0$. Since lenders are competitive, in expectation risk-neutral lenders receive exactly the risk-free rate. For an entrepreneur of type $J$, who innovates with probability $a_{J} \mu\left(\frac{Z_{i t}}{A_{i t}}\right)$, this means having to repay one over this amount (per each dollar borrowed) in case of success.

So, the pre-consumption-tax net present value (NPV) of the project for an entrepreneur of type $J$ contributing $E_{i t}$ in equity is

$$
\begin{aligned}
N P V_{i t}^{J}\left(Z_{i t} \mid \tau_{\pi}\right) & \equiv a_{J} \mu\left(\frac{Z_{i t}}{A_{i t}}\right)\left[\Pi_{i, t+1}\left(1-\tau_{\pi}\right)-\frac{1}{a_{J} \mu\left(\frac{Z_{i t}}{A_{i t}}\right)}\left(Z_{i t}-E_{i t}\right)\right]-E_{i t} \\
& =a_{J} \mu\left(\frac{Z_{i t}}{A_{i t}}\right) \Pi_{i, t+1}\left(1-\tau_{\pi}\right)-Z_{i t},
\end{aligned}
$$

which does not depend on $E_{i t}{ }^{6}$

Because an entrepreneur that becomes an intermediate good producer advances productivity by step $\gamma$, and given that the solution to the intermediate good producer's problem implies productivity-adjusted profits are constant across industries and over time, adjusting $N P V_{i t}^{J}$ for productivity $A_{i t}$ implies

$$
n p v_{i t}^{J}\left(z_{i t} \mid \tau_{\pi}\right)=a_{J} \mu\left(z_{i t}\right) \gamma \pi\left(1-\tau_{\pi}\right)-z_{i t} .
$$

\footnotetext{
${ }^{6}$ To keep the model tractable, we abstract from the issue of deductibility of interest payments.
} 
The entrepreneur's optimal choice of productivity-adjusted effort satisfies the first order condition

$$
1=a_{J} \mu^{\prime}\left(z_{i t}\right) \gamma \pi\left(1-\tau_{\pi}\right)
$$

and is hence constant across industries with the same type of entrepreneur, and over time. We now drop the it subscript, and let $z_{J}$ denote productivityadjusted effort by an entrepreneur of type $J$, and $\hat{z}_{J}\left(\tau_{\pi}\right)$ his optimal effort. It is easy to see that $\hat{z}_{H}\left(\tau_{\pi}\right)>\hat{z}_{L}\left(\tau_{\pi}\right)$.

All else equal, lowering the tax rate on profit encourages research. The consumption tax rate has no effect on research because it symmetrically affects the costs and benefits of the decision (this is why we express NPV in pre-consumption-tax value units). Additionally, because capital markets are perfect, the effort decision is independent of the extent of equity financing and thus of the entrepreneur's wealth. Consequently, the labor tax rate does not impact research effort either.

\subsection{Aggregation and the Government Budget Constraint}

Let "industry of type $J$ " indicate an industry in which the entrepreneur is of type $J$. Aggregation is considerably simplified by the linear dependence of industry-specific variables on productivity.

Average research effort equals

$$
\bar{z} \equiv \frac{1}{2} z_{H}+\frac{1}{2} z_{L}
$$

A measure

$$
\bar{\mu}\left(z_{H}, z_{L}\right) \equiv \frac{1}{2} a_{H} \mu\left(z_{H}\right)+\frac{1}{2} a_{L} \mu\left(z_{L}\right)
$$

of industries innovate each period. Since the allocation of talent and the outcome of research are independent across industries, and they do not depend on industry productivity, we can write the evolution of average productivity as

$$
A_{t+1}=\bar{\mu}\left(z_{H}, z_{L}\right) \gamma A_{t}+\left(1-\bar{\mu}\left(z_{H}, z_{L}\right)\right) A_{t}=\left(1+\bar{\mu}\left(z_{H}, z_{L}\right)(\gamma-1)\right) A_{t} .
$$


The analysis in this paper restricts itself to comparisons across balanced growth paths since $r=0$ ensures there are no transitional dynamics in this model. On a balanced growth path, all aggregate variables grow at the same rate as average productivity:

$$
g\left(z_{H}, z_{L}\right) \equiv 1+\bar{\mu}\left(z_{H}, z_{L}\right)(\gamma-1)
$$

Consider the taxable flows. There is a unit measure of monopolists, each making productivity-adjusted profits $\pi$, and there are $L$ agents working in each industry, each earning productivity-adjusted labor income $w$. Productivityadjusted aggregate consumption $c$ satisfies

$$
c=y-i\left(z_{H}, z_{L}\right)-\bar{z}
$$

where $y$ is productivity-adjusted aggregate output and $i\left(z_{H}, z_{L}\right)$ is the productivityadjusted aggregate quantity of consumption goods invested into the production of next-period intermediate goods. ${ }^{7}$ Let $x$ denote the taxable flows. Then, $x=\left(\begin{array}{lll}\pi & L w & c\end{array}\right)^{\prime}$.

The government has an exogenous spending requirement, $S_{t} \geq 0$ that also exogenously grows at a rate $g$. Government spending is akin to destroying resources: it produces no utility nor economic benefit to the agents.

A set of tax schedules must imply net tax transfers that satisfy the government budget constraint, given by

$$
\tau_{\pi} \pi+\tau_{w} L w+\tau_{c} c=s,
$$

where $s$ is productivity-adjusted government spending.

\footnotetext{
${ }^{7}$ This assumes, without loss of generality, that any consumption good left over after research and investment is immediately consumed. See Appendix A for a derivation of $w, y$ and $i\left(z_{H}, z_{L}\right)$.
} 


\section{A Model of Asymmetric Information}

Now suppose that the entrepreneur's type is private information. In this asymmetric information environment, the low types may have an incentive to mimic the high types' choice of self-investment and leverage, in order to pay a lower interest rate. Because a lower rate only applies to external financing, the low types' gains from mimicking decrease with self-investment by the high types, and increases with their leverage. At the expense of scale, the high types can strategically differentiate themselves from the low types by contributing as much as possible to their projects and choosing a low leverage ratio. Otherwise, the high types can pursue a large project while paying an adverse selection premium on borrowed funds. ${ }^{8}$ It turns out there also exists a third equilibrium in which the high types can differentiate themselves by choosing an excessively high leverage ratio. In the first part of this section, we describe the first two equilibria in an intuitive way (their formal derivation is provided in Appendix B). We conclude the section by briefly describing the third equilibrium.

If $\hat{z}_{H}\left(\tau_{\pi}\right) \leq\left(1-\tau_{w}\right) w$, asymmetric information does not affect investment decisions, since all entrepreneurs have enough net worth to finance their optimal investment decisions through equity contributions. It is then $z_{J}=\hat{z}_{J}\left(\tau_{\pi}\right)$ as in the model with perfect information. ${ }^{9}$ We then only need to consider the case $\left(1-\tau_{w}\right) w<\hat{z}_{H}\left(\tau_{\pi}\right)$. In what follows, we express all variables in productivity-adjusted terms.

\footnotetext{
${ }^{8}$ The intuition of this setup is akin to ?. In that paper, because self-investment limits an entrepreneur's ability to diversify, the entrepreneur can credibly signal the quality of his project by owning a larger share of its equity. In this paper, because relying of outside financing can attract low-talent entrepreneurs posing as high-talent ones, cause adverse selection, and hence raise the high-talent entrepreneur's financing costs, the high-talent entrepreneur can credibly signal the quality of his project by contributing a large enough share of the research capital.

${ }^{9}$ More precisely, there only exists a separating equilibrium in which $z_{J}=\hat{z}_{J}\left(\tau_{\pi}\right)$, with any combination of equity and external financing being possible. See Appendix B for more details.
} 


\subsection{The Low Type's Problem}

When lenders are unable to observe entrepreneurial talent, low-talent entrepreneurs may have an incentive to mimic the high types, in order to pay interest rate $\frac{1}{a_{H} \mu(z)}<\frac{1}{a_{L} \mu(z)}$ on external financing. For a separating equilibium to exist in which type $J$ pays interest rate $\frac{1}{a_{J} \mu(z)}$, such an incentive cannot be in place. Based on this requirement, we now derive a first necessary condition for a separating equilibrium.

In any separating equilibrium, the low-types must choose their optimal effort with perfect information, $\hat{z}_{L}\left(\tau_{\pi}\right) .{ }^{10}$ Consider a separating equilibrium in which the high types invest $z>\left(1-\tau_{w}\right) w$, contributing their entire after-tax labor income as equity. Then, the condition for the low types not to mimic the high types (and for this separating equilibrium to exist) is

$$
\begin{aligned}
\widetilde{n p v}^{L}\left(z \mid \tau_{\pi}, \tau_{w}\right) & \equiv a_{L} \mu(z)\left\{\gamma \pi\left(1-\tau_{\pi}\right)-\frac{1}{a_{H} \mu(z)}\left[z-\left(1-\tau_{w}\right) w\right]\right\}-\left(1-\tau_{w}\right) w \\
& =a_{L} \mu(z) \gamma \pi\left(1-\tau_{\pi}\right)-\frac{a_{L}}{a_{H}}\left[z-\left(1-\tau_{w}\right) w\right]-\left(1-\tau_{w}\right) w \\
& \leq n p v^{L}\left(\hat{z}_{L}\left(\tau_{\pi}\right) \mid \tau_{\pi}\right) .
\end{aligned}
$$

The term $\widetilde{n p v}^{L}\left(z \mid \tau_{\pi}, \tau_{w}\right)$ is the net present value of the project for a lowtalent entrepreneur who successfully mimic a high-talent one. It must be lower than the low type's net present value from investing $\hat{z}_{L}\left(\tau_{\pi}\right)$, or else the low type would mimic the high type, and the separating equilibrium would collapse.

The bottom two lines of Figure 3.1 illustrate. The solid line is the low type's net present value with perfect information. Because the probability function $\mu($.$) is increasing and strictly concave while the research cost is linear, the$ curve increases at a diminishing rate at first, reaches a unique maximum at $\hat{z}_{L}\left(\tau_{\pi}\right)$, and then decreases. At a separating equilibrium, the low type obtains payoff $n p v^{L}\left(\hat{z}_{L}\left(\tau_{\pi}\right) \mid \tau_{\pi}\right)$. The dashed line represents the payoff that the low type could obtain by successfully mimicking a high type. The low type does

\footnotetext{
${ }^{10}$ To see this, suppose $z_{L} \neq \hat{z}_{L}\left(\tau_{\pi}\right)$ at a separating equilibrium. Since this is a separating equilibrium, the low types would have to be offered rate $\frac{1}{a_{L} \mu\left(\hat{z}_{L}\left(\tau_{\pi}\right)\right)}$, and their payoff would have to be $n p v\left(z_{L} \mid \tau_{\pi}\right)$. But, by choosing $\hat{z}_{L}\left(\tau_{\pi}\right)$, they could have not been offered a higher rate in equilibrium, and they would have thus obtained at least $n p v\left(\hat{z}_{L}\left(\tau_{\pi}\right) \mid \tau_{\pi}\right)>n p v\left(z_{L} \mid \tau_{\pi}\right)$.
} 


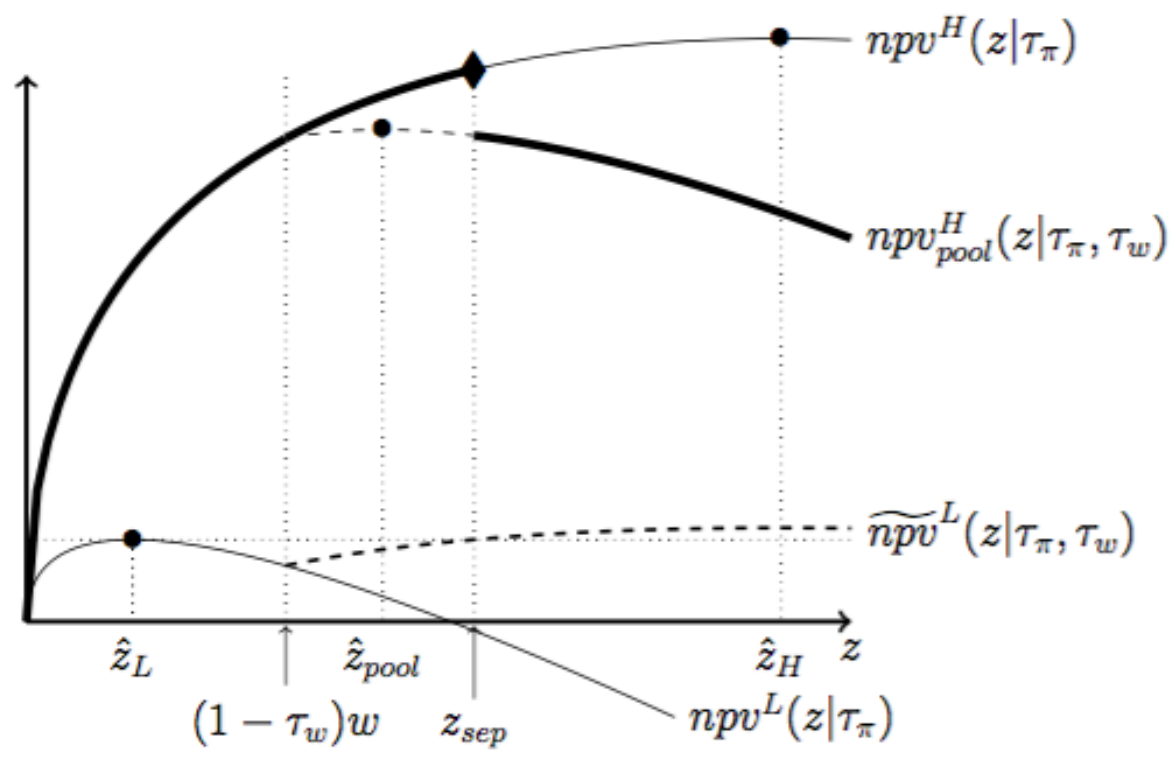

Figure 3.1: High type is strategically constrained

not have an incentive to mimic if $z$ is low (between $\left(1-\tau_{w}\right) w$ and $z_{\text {sep }}$ ) but if it is high (immediately above $z_{\text {sep }}$ ), then he does. Intuitively, a high $z$ is associated with a high level of leverage of high-talent entrepreneurs, and this attracts a low-talent entrepreneur who is less likely to repay his debt.

Note that the decision to mimic depends on the profit tax rate, which affects the low type's incentive to conduct research, and on the labor tax rate, which affects the high type's leverage and thus the low type's incentive to mimic. In constrast, the consumption tax rate does not affect the decision to mimic because it applies to the decision's benefits and costs symmetrically: post-consumption-tax, both sides of equation 3.1 are divided by $1+\tau_{c}$.

Before continuing, we formally define $z_{\text {sep }}$ as the minimum solution to

$$
\widetilde{n p v}^{L}\left(z \mid \tau_{\pi}, \tau_{w}\right)=n p v^{L}\left(\hat{z}_{L}\left(\tau_{\pi}\right) \mid \tau_{\pi}\right)
$$

or $z_{\text {sep }}=\hat{z}_{H}\left(\tau_{\pi}\right)$ if such solution does not exists. The full properties of $z_{\text {sep }}$ are derived in Appendix B. Here, it is sufficient to note that, in the range where a separating equilibrium exists, $\hat{z}_{H}\left(\tau_{\pi}\right) \geq z_{\text {sep }}>\left(1-\tau_{w}\right) w$, and it is increasing 
in $\left(1-\tau_{w}\right) w$ before reaching its maximum.

\subsection{The High Type's Problem}

In the separating equilibrium discussed in the previous section, the high-talent entrepreneurs cannot invest more than $z_{\text {sep }}$, or else the low types would want to mimic them. A second condition for the separating equilibrium to exist is that the high-talent entrepreneurs prefer to pursue less research but to be in a separating equilibrium without adverse selection, than to choose a higher research effort with adverse selection. Suppose lenders believe that those investing more than $z_{\text {sep }}$ (and contributing their entire income as equity) are high and low types with equal probability. They then require a payment $\frac{1}{\bar{a} \mu(z)}$, (where $\bar{a} \equiv \frac{1}{2} a_{H}+\frac{1}{2} a_{L}$ ) from any borrower to compensate for the risk of loaning to an entrepreneur of average talent. The high types' decision hinges on the relative benefit of a higher probability of innovation if they invest more than $z_{\text {sep }}$, versus the higher costs of financing that adverse selection entails. The condition for the high types to prefer to avoid adverse selection is

$$
\begin{aligned}
n p v_{\text {pool }}^{H}\left(z \mid \tau_{\pi}, \tau_{w}\right) & \equiv a_{H} \mu(z)\left\{\gamma \pi\left(1-\tau_{\pi}\right)-\frac{1}{\bar{a} \mu(z)}\left[z-\left(1-\tau_{w}\right) w\right]\right\}-\left(1-\tau_{w}\right) w \\
& =a_{H} \mu(z) \gamma \pi\left(1-\tau_{\pi}\right)-\frac{a_{H}}{\bar{a}}\left[z-\left(1-\tau_{w}\right) w\right]-\left(1-\tau_{w}\right) w \\
& \leq n p v^{H}\left(z_{\text {sep }} \mid \tau_{\pi}\right),
\end{aligned}
$$

for all $z>z_{\text {sep }}$. The term $n p v_{\text {pool }}^{H}\left(z \mid \tau_{\pi}, \tau_{w}\right)$ is the net present value of the project for a high-talent entrepreneur whom lenders cannot distinguish from a low type. For all $z>z_{\text {sep }}$, it must be lower than the entrepreneur's net present value when investing $z_{\text {sep }}$, or else the high type would choose $z$ and the separating equilibrium would collapse. The top two lines of Figure 3.1 illustrate. The thin solid line (partially covered by a thick line to be discussed momentarily) is the high type's net present value with perfect information. With perfect information, the high type maximises such value by selecting effort $\hat{z}_{H}\left(\tau_{\pi}\right)$. With asymmetric information, the high type can invest up to 


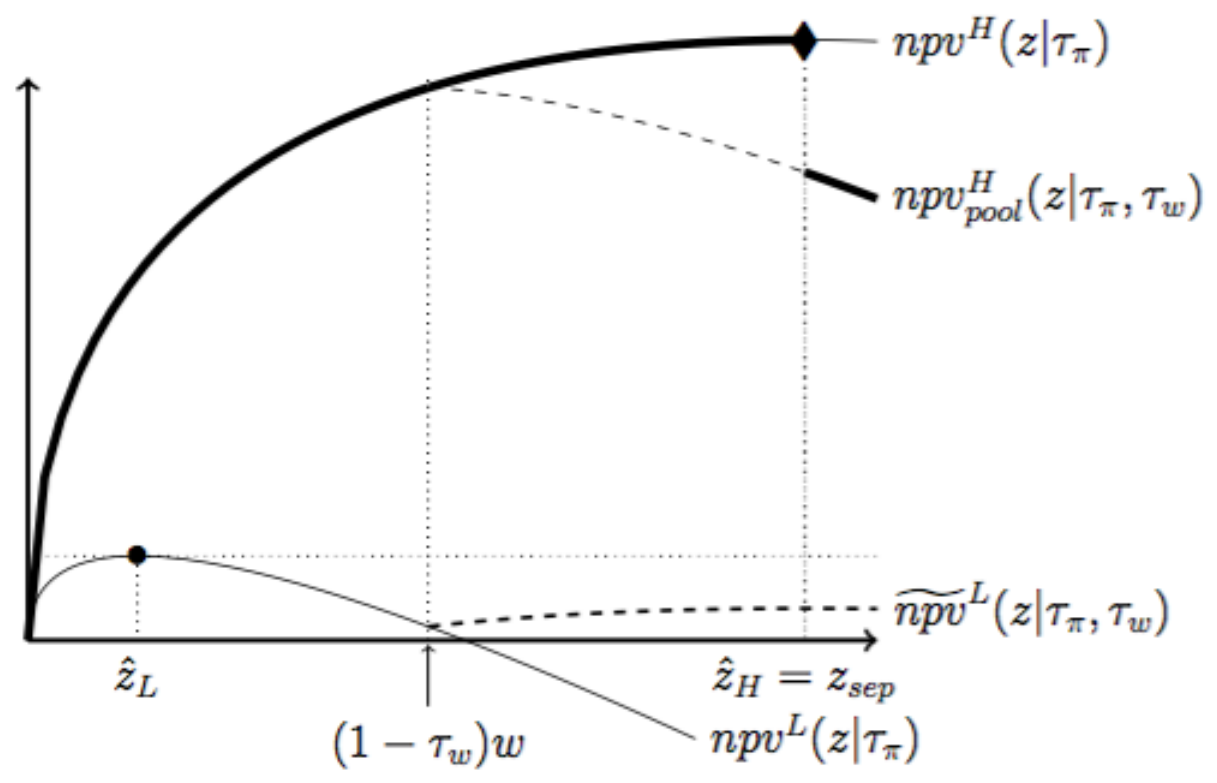

Figure 3.2: High type is unconstrained

$z_{\text {sep }}$ at perfect information interest rate, or invest more and face a higher cost of financing due to adverse selection. His payoff in the latter case is represented by the dashed line (also partially covered by a thick solid line). At the effort threshold $z_{\text {sep }}$, the dashed line is always lower than the solid line, due to the adverse selection premium the entrepreneur must pay on the amount borrowed - the difference between net-worth and the effort threshold. The slope of the curve is also smaller, since the marginal cost of research on it is $\frac{a_{H}}{\bar{a}}>1$.

With asymmetric information, the high types select the level of effort that maximises the function represented by the thick solid line. The solution to the high type's optimal effort problem has two cases, where the entrepreneur's choice of effort is either equal to, or above $z_{\text {sep }}$. Figure 3.1 represents the first case. Here $z_{\text {sep }}$ is high enough that the entrepreneur prefers to avoid adverse selection, and a separating equilibrium exists. The entrepreneur is said to be strategically constrained, in the sense that even if he does not pay the adverse selection premium, his choice is affected by it: he is forced to invest less than with perfect information, and must pay a higher interest rate 


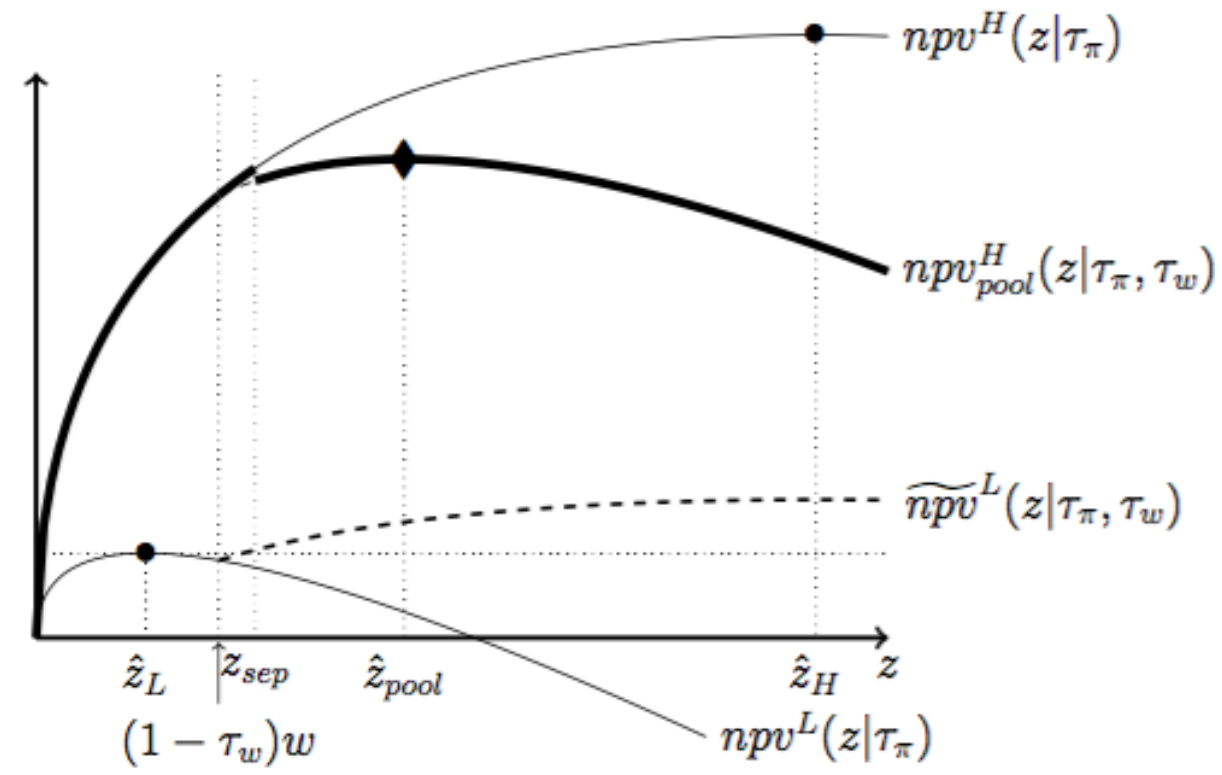

Figure 3.3: High type is constrained

(since $\left.\frac{1}{a_{H} \mu\left(z_{s e p}\right)}>\frac{1}{a_{H} \mu\left(\hat{z}_{H}\right)}\right)$. Note that the entrepreneur does not need to be strategically constrained at a separating equilibrium. In Figure 3.2, $\left(1-\tau_{w}\right) w$ is so high that the low types never find it optimal to mimic the high types. In this case, $z_{\text {sep }}=\hat{z}_{H}\left(\tau_{\pi}\right)$, and the adverse selection problem is irrelevant. The entrepreneur is unconstrained. The second case is represented in Figure 3.3. Here, $z_{\text {sep }}$ is so low that the high types decides to put more effort into innovation even if this implies paying an adverse selection premium. The high-talent entrepreneur is constrained.

In the last case, the separating equilibrium collapses. We show in the Appendix that there then exists a pooling equilibrium in which the high types maximise $n p v_{\text {pool }}^{H}\left(z \mid \tau_{\pi}, \tau_{w}\right)$, and the low types maximise a similar function with $a_{H}$ replaced everywhere by $a_{L}$. Optimal effort by type $J$ satisfies

$$
1=\bar{a} \mu^{\prime}(z) \gamma \pi\left(1-\tau_{\pi}\right)
$$

and is thus the same for the two types. We denote such a level of effort by 
$\hat{z}_{\text {pool }}\left(\tau_{\pi}\right)$, where $\hat{z}_{L}\left(\tau_{\pi}\right)<\hat{z}_{\text {pool }}\left(\tau_{\pi}\right)<\hat{z}_{H}\left(\tau_{\pi}\right)$. We show in Appendix B that, at the minimum $z_{\text {sep }}$ such that the high type is strategically constrained, it is $\hat{z}_{L}\left(\tau_{\pi}\right)<\left(1-\tau_{w}\right) w<z_{\text {sep }}<\hat{z}_{\text {pool }}\left(\tau_{\pi}\right)$.

As this discussion suggests, the threshold $z_{\text {sep }}$ plays a key role in determining the equilibrium. If it is equal to $\hat{z}_{H}\left(\tau_{\pi}\right)$ or just below it, the high types are, respectively, unconstrained and strategically constrained; if it gets closer to $\hat{z}_{L}\left(\tau_{\pi}\right)$, or falls below it, the high types are constrained. What is important is that $z_{\text {sep }}$ is an increasing function of the amount of equity that the high types are able to contribute, $\left(1-\tau_{w}\right) w$. The tax on labor, then, is a key determinant of the equilibrium.

Lemma 1. There exist $\underline{\tau}_{w}$ and $\bar{\tau}_{w}$, with $-\infty<\underline{\tau}_{w}<\bar{\tau}_{w}<1$ such that:

- If $\tau_{w} \leq \underline{\tau}_{w}$, the high types are unconstrained: a separating equilibrium realises, where $z_{\text {sep }}=\hat{z}_{H}\left(\tau_{\pi}\right)$.

- If $\tau_{w} \in\left(\underline{\tau}_{w}, \bar{\tau}_{w}\right]$, the high types are strategically constrained: a separating equilibrium realises, where $z_{\text {sep }} \in\left(\hat{z}_{L}\left(\tau_{\pi}\right), \hat{z}_{H}\left(\tau_{\pi}\right)\right)$.

- If $\tau_{w}>\bar{\tau}_{w}$, the high types are constrained: a pooling equilibrium realises.

If $\tau_{w} \in\left(\underline{\tau}_{w}, \bar{\tau}_{w}\right], z_{\text {sep }}$ is decreasing in $\tau_{w}$, increasing in $\tau_{\pi}$.

It is worth highlighting that, for $\tau_{w} \in\left(\underline{\tau}_{w}, \bar{\tau}_{w}\right]$, the threshold $z_{s e p}$ - and thus investment by the high types - is increasing in $\tau_{\pi}$. The intuition for this surprising result is as follows. On the one hand, since the high types are strategically constrained, they are not constrained by their incentives to do research: thus, an increase in $\tau_{\pi}$ does not induce them to invest less. On the other hand, an increase in $\tau_{\pi}$ weakens the incentives for the low types to do research. This makes it less attractive for them to mimic the high types, since to do so would involve investing even more in research.

This suggests a more general result: when the high types are strategically constrained, lower profit margins (lower $\pi$ ) may increase innovation, because they lead to more "survival of the fittest": low-talent entrepreneurs will invest less (a lower $\hat{z}_{L}\left(\tau_{\pi}\right)$ ), but high-talent entrepreneurs will invest more (a higher $\left.z_{s e p}\right)$. 
This result is important, because it suggests a new way to reconcile Schumpeterian theory with the empirical finding described in ? of an inverted-U relationship between product market competition and innovation. In the standard Schumpeterian model, more competition, as captured by a lower $\pi$, always reduces innovation (e.g. ?, p. 90-92). Now consider our model, and suppose we are at a separating equilibrium with $z_{\text {sep }}<\hat{z}_{H}\left(\tau_{\pi}\right)$. When competition is low (and $\pi$ is high), agents have a strong incentive to conduct research. Because of asymmetric information, however, there is also a strong incentive for the low types to mimic the high types, which leads to little investment by the latter. In terms of Figure 3.1, the two npv lines are quite steep, and, on the opposite sides of $\left(1-\tau_{w}\right) w, \hat{z}_{L}\left(\tau_{\pi}\right)$ is high and $z_{\text {sep }}$ is low. Now suppose that competition begins to increase, so that profit margins narrow. By inducing more survival of the fittest (a lower $\hat{z}_{L}\left(\tau_{\pi}\right)$ and a higher $z_{s e p}$ ), this may increase innovation. However, this positive relation between competition and innovation cannot last. As competition increases further, the high types eventually become unconstrained. After this point, further increases in competition must reduce the amount of innovation, since they weaken the incentives of both types to conduct research. ${ }^{11}$

\subsection{The Effects of Tax Policy}

It is apparent from equations (2.1) and (3.2) that both at a separating and at a pooling equilibrium, the low types' optimal research effort only depends on the tax on profit. A similar logic applies to the high types at a separating equilibrium in which they are unconstrained, or at a pooling equilibrium. However, at a separating equilibrium where the high-types are strategically constrained, the response of their research effort to a policy change is determined by the impact of the change on the threshold effort $z_{s e p}$. According to Lemma 1, the only way to raise the high type's research effort in this case is to lower the tax on labor income, or to increase the tax on profit. This leads to the following

\footnotetext{
${ }^{11}$ Our result that $\hat{z}_{L}\left(\tau_{\pi}\right)$ and $z_{\text {sep }}$ move further apart as competition increases resonates with the other empirical finding in ?, that more competitive industries are less "neck-andneck". But we do not want to push this point here.
} 
proposition.

Proposition 2. Lowering the tax on profit always boosts research effort by the low types, and by the high types at a separating equilibrium in which they are unconstrained $\left(z_{\text {sep }}=\hat{z}_{H}\left(\tau_{\pi}\right)\right)$, or at a pooling equilibrium. At a separating equilibrium in which the high types are strategically constrained $\left(z_{\text {sep }}<\hat{z}_{H}\left(\tau_{\pi}\right)\right)$, lowering the labor income tax boosts their research effort, and so does increasing the tax on profit.

Proposition 2 has multiple interpretations. First, there may be a motive for redistribution from established business owners to workers, since it may be beneficial to tax profits to subsidize labor income. This happens when the high types are strategically constrained, if the benefit from more research by the high types outweighs the cost of less research by the low types. This benefit of redistribution stems from the asymmetric information problem. Thinking further, however, increasing profit taxes cannot be an effective way to increase research effort very much, since as taxes keep increasing eventually high-talent entrepreneurs become unconstrained by their relatively high net-worth and poor incentives, at which point further increases in the profit tax are growthreducing. On the other hand, taxing consumption to finance reductions in the tax rates on labor avoids this limitation. It relaxes the financial constraints of the high-types without worsening the incentives of the low types, nor those of the high-types after they become unconstrained. It thus unambiguously spurs innovation and growth. ${ }^{12}$

This leads to another subtle and important interpretation of the proposition. If governments believe financial constraints hold back entrepreneurial activity, they should restructure their sources of tax revenue. They should rely on consumption rather than income taxation. ${ }^{13}$ This result resonates with the

\footnotetext{
12? make a related point when studying the effects of tax policy on the decisions of financially constrained farmers. They argue that lowering the income tax allows constrained farmers to accumulate networth faster while a consumption tax does not distort their investment decisions, so that as a net result replacing the income tax with a consumption tax relaxes farmers' financing constraints.

${ }^{13}$ Of course, this result is special to the the assumptions of this model. Consumption taxes neither cause tax evasion nor do they interact with labor effort (there is no disutility of labor).
} 
literature on fundamental tax reform, which has for some time argued in favor of transitioning from an income-based to a consumption-based tax system (e.g., ?). Our paper proposes a new channel through which tax reform may improve efficiency: namely, it may increase the innovation rate, helping to rectify the endogenous growth externalities that tend to make it smaller than the social optimum.

\subsection{An Alternative Separating Equilibrium}

The separating equilibrium discussed so far is supported by the belief that those who invest more than $z_{\text {sep }}$ (contributing their entire income as equity) are high and low types with equal probability. However, when we challenge this belief using standard dominance-based refinements, as in ?, p. 469, we find that it needs to be qualified as follows: lenders should, in addition, believe that those who invest more than some $\bar{z}_{s e p} \geq \hat{z}_{H}\left(\tau_{\pi}\right)$ (contributing their entire income as equity) are high types. The intuition is straightforward. In Figure 3.1, the curve $\widetilde{n p v}^{L}$ cuts the dotted horizontal line twice, at $z_{\text {sep }}$ and at some $\bar{z}_{\text {sep }} \geq \hat{z}_{H}\left(\tau_{\pi}\right)$. If an entreprenur invested more than $z>\bar{z}_{\text {sep }}$, he would reasonably have to be a high type, since that action is dominated for the low types for any interest rate that they may be offered in equilibrium.

Once we refine the lenders' beliefs in such a way, the strategically constrained high types have an additional option: they can choose $\bar{z}_{\text {sep }}$ (still contributing their entire income in equity), and differentiate themselves through an excessively high leverage ratio that no low-talent entrepreneur would dare to undertake. At this alternative option, the high types pay a lower interest rate than with perfect information (since $\left.\frac{1}{a_{H} \mu\left(\bar{z}_{s e p}\right)}<\frac{1}{a_{H} \mu\left(\hat{z}_{H}\right)}\right)$. It turns out that the high types are exactly indifferent between this new option and $z_{\text {sep }}$, and it is then impossible to predict which one they will choose in equilibrium. ${ }^{14}$ There could be industries in which the high types choose $z_{\text {sep }}$ in equilibrium, and others in which they choose $\bar{z}_{\text {sep }}$. This multiplicity of equilibria only applies to

\footnotetext{
${ }^{14}$ It is straightforward to see why. First, note that we can write $n p v^{H}(z)=\frac{a_{L}}{a_{H}} \widetilde{n p v}^{L}(z)-$ $\frac{a_{H}-a_{L}}{a_{H}}\left(1-\tau_{w}\right) w$. Then, $n p v^{H}(z)$ is a linear transformation of $\widetilde{n p v}^{L}(z)$, and $\widetilde{n p v}^{L}\left(z_{s e p}\right)=$ $\frac{a_{H}}{n p v^{L}}\left(\bar{z}_{\text {sep }}\right)$ implies $n p v^{H}\left(z_{\text {sep }}\right)=n p v^{H}\left(\bar{z}_{\text {sep }}\right)$.
} 
the case of strategically constrained high types, while the other two cases are unchanged. Also unchanged are the thresholds for $\tau_{w}$ that determine which case is the relevant one, as enunciated by Lemma 1. Finally, it is possible to prove that no other separating equilibrium survives the dominance-based refinements mentioned above. ${ }^{15}$

If we adopt this multiplicity of equilibria, our results need to be qualified. First and foremost, the discussion in the last two sections only partially applies to industries in which a strategically constrained high type selects effort $\bar{z}_{\text {sep }}$. To see why, note that, symmetrically to $z_{s e p}, \bar{z}_{\text {sep }}$ is increasing in $\tau_{w}$, decreasing in $\tau_{\pi}$. In those industries, then, a higher tax on profit (or higher competition) leads to a lower research effort by the entrepreneur, just like in the standard Schumpeterian model (though in our model the entrepreneur actually gains from the change, since he can get closer to his optimal investment level). However, it is still true that the government benefits from a greater capacity to tax consumption, since this allows it to independently influence research by the two types of entrepreneurs. This last point will also imply that optimal policy, the next focus of our attention, is qualitatively unaffected by the multiplicity of equilibria. To the discussion of optimal policy we now turn.

\section{Optimal Policy}

In the standard Schumpeterian growth model where there is no informational friction and financial markets are perfect, the labor income of entrepreneurs does not affect their research effort, and hence nor does the extent to which the government taxes their labor income. Consequently, the government can implement the first best allocation by taxing labor income to finance profit subsidies, independent on any restriction on consumption taxation.

With asymmetric information, however, because the government must jointly

\footnotetext{
${ }^{15}$ Intuitively, to contribute $\left(1-\tau_{w}\right) w$ in equity and select $z \in\left(\left(1-\tau_{w}\right) w, z_{\text {sep }}\right]$ or $z \geq \bar{z}_{\text {sep }}$ is a dominated action for the low types. It follows that beliefs cannot allocate a positive probability to them undertaking such actions, which are then all available to the high types at any separating equilibrium. Then, at any separating equilibrium, the high types must contribute $\left(1-\tau_{w}\right) w$ in equity, and select $z_{\text {sep }}$ or $\bar{z}_{\text {sep }}$.
} 
subsidize labor income and profits to implement the first best allocation, the government relies more on consumption taxation. Consequently, we show how restricting the government's ability to tax consumption leads to a second best situation in which the first best allocation is not implementable and why in the face of a severe restriction on consumption taxation the government finds it optimal to implement an equilibrium with adverse selection.

\subsection{First Best Allocation}

The government behaves as a social planner whose objective is to maximize the expected total consumption across time (and generations) discounted at rate $0<\beta<1$. The planner's objective, normalized for initial average productivity $A_{0}$, is

$$
v\left(z_{H}, z_{L}\right)=\sum_{t=0}^{\infty}\left(\beta g\left(z_{H}, z_{L}\right)\right)^{t} \frac{C_{0}}{A_{0}}=\frac{c\left(z_{H}, z_{L}\right)}{1-\beta g\left(z_{H}, z_{L}\right)} .
$$

Since productivity-adjusted investment increases with research effort (see Appendix A), equation (2.2) implies productivity-adjusted consumption unambiguously decreases with research effort, $\frac{\partial c\left(z_{H}, z_{L}\right)}{\partial z_{J}}=-\frac{1}{2}-\frac{\partial i\left(z_{H}, z_{L}\right)}{\partial z_{J}}<0$. On the other hand, the growth rate of productivity increases with research effort, and hence so does the denominator of the objective. First best research effort by type $J, z_{J}^{*}$ is given by

$$
z_{J}^{*}=\arg \max _{z_{J}} v\left(z_{H}, z_{L}\right)
$$

which implies

$$
\frac{-\frac{\partial c\left(z_{H}^{*}, z_{L}^{*}\right)}{\partial z_{J}^{*}}}{\frac{1}{2} a_{J} \mu^{\prime}\left(z_{J}^{*}\right)}=\frac{\beta(\gamma-1) c\left(z_{H}^{*}, z_{L}^{*}\right)}{1-\beta g\left(z_{H}^{*}, z_{L}^{*}\right)} .
$$

As before, denote by $\hat{z}_{J}\left(\tau_{\pi}\right)$ the entrepreneur's privately-optimal research effort, and in particular $\hat{z}_{J}(0)$ under laissez-faire. Compare (4.1) with

$$
\frac{1}{a_{J} \mu^{\prime}\left(\hat{z}_{J}(0)\right)}=\gamma \pi
$$

the private research effort equation under laissez-faire. As in ?, there are four 
effects that determine the disparity between the private and social returns to innovation. First, an entrepreneur only considers the one-period ahead value of innovation, while the government values the entire discounted stream of future benefits ("spillover effect"). Second, the government measures the effect of innovation on consumption $c$ rather than profit $\pi$; this is called the appropriability effect. Third, the government accounts for the business-stealing effect by scaling the consumption gain by $\gamma-1$ rather than $\gamma$. Fourth, the monopoly distortion effect implies that the monopolist looks at the private cost rather than the social cost of research. The spillover and appropriability effects tend to make laissez-faire research lower than the optimum, while the business-stealing and monopoly distortion effects push research effort up. The net direction depends on the strength of each effect.

From equation (4.1), we see that, at the first best allocation, ${ }^{16}$

$$
a_{H} \mu^{\prime}\left(z_{H}^{*}\right)=a_{L} \mu^{\prime}\left(z_{L}^{*}\right)
$$

which implies $z_{H}^{*}>z_{L}^{*}$. It is socially optimal that high-talent entrepreneurs, who are more likely to be successful, invest more in research.

\subsection{Model with Perfect Information}

Consider first the benchmark model with perfect information. Under what conditions is the first best implementable?

Definition. Policy $\tau^{*}$ implements the first best research effort $z_{H}^{*}, z_{L}^{*}$ in the model with perfect information if $(a) \tau_{\pi}^{*}$ satisfies

$$
1=a_{J} \mu^{\prime}\left(z_{J}^{*}\right) \gamma \pi\left(1-\tau_{\pi}^{*}\right)
$$

for $J=\{H, L\}$, and (b) the policy $\tau^{*}$ satisfies the government budget constraint (2.3).

\footnotetext{
${ }^{16}$ Since $-\frac{\partial c\left(z_{H}^{*}, z_{L}^{*}\right)}{\partial z_{J}^{*}}=\alpha^{\frac{2}{1-\alpha}}(\gamma-1) \frac{1}{2} a_{J} \mu^{\prime}\left(z_{J}^{*}\right) L+\frac{1}{2}$, (4.1) can be written as $\frac{1}{a_{J} \mu^{\prime}\left(z_{J}^{*}\right)}=$ $\frac{\beta(\gamma-1) c\left(z_{H}^{*}, z_{L}^{*}\right)}{1-\beta g\left(z_{H}^{*}, z_{L}^{*}\right)}-\alpha^{\frac{2}{1-\alpha}}(\gamma-1) L$.
} 
Equation (4.2) implies that vector $\tau^{*}$ exists, since there exists $\tau_{\pi}^{*}$ such that equation (4.3) holds for both types of entrepreneurs. Given $\tau_{\pi}^{*}$, the government budget constraint requires the tax rates on labor and consumption to balance the budget. But, with perfect information, these adjustments do not impact research effort. So, any feasible combination of taxes on labor and consumption able to finance $\tau_{\pi}^{*}$ implements the optimal policy.

Although both labor and consumption taxes can be used to implement the first best, governments for either political or practical reasons only rely so much on consumption taxes. It is more likely that, were the government to seriously attempt to narrow the gap between the private and social returns to research, the source of revenue would be income taxes. The following assumption ensures that the use of the consumption tax is not necessary to implement the first best allocation in the benchmark model and in the special case of a zero interest rate to which this paper restricts itself.

Assumption 3. The first best allocation $z_{H}^{*}, z_{L}^{*}$ is higher than laissez-faire $\left(z_{H}^{*}>\hat{z}_{H}(0), z_{L}^{*}>\hat{z}_{L}(0)\right)$, but low enough such that if the government [in the benchmark model] finances the profit subsidy required to implement it solely through a tax on labor income, the agents' research and investment choices are consistent with a risk-free interest rate equal to zero.

Assumption 3 ensures that, no matter how severe a restriction on consumption taxes the government faces, the first best is implementable in the benchmark model. Then, the only impediment to implementing the first best allocation is the constraint imposed on tax rates by the adverse selection problem (see the next section).

\subsection{Model with Asymmetric Information}

Now consider the model with asymmetric information. The potential adverse selection problem has no effect on the first best allocation. It remains true that, if the government was able to, it would want to induce the first best allocation. However, we show that the government can only implement the first best in the absence of severe restrictions on consumption taxation. 
It is also possible that, in pursuing its optimal policy, the government decides to allow for a pooling equilibrium with adverse selection. In this type of equilibrium, the socially optimal research effort by the high types must be lower than at the first best, because their effort is exactly (and wastefully) replicated by the low types. We call the optimal allocation among pooling equilibria with adverse selection the constrained first best allocation, as it is conceptually similar to the first best allocation, but accounts for the resource loss from the excessive investment by the low types.

We begin by discussing implementability of the first best. We then derive the constrained first best. Finally, we turn to the second best allocation in the presence of an exogenous restriction on the rate of consumption taxation.

\subsubsection{First Best}

Definition. Policy $\tau_{\text {sep }}^{*}$ implements the first best research effort $z_{H}^{*}, z_{L}^{*}$ in a separating equilibrium with no adverse selection if $(a) \tau_{\pi, \text { sep }}^{*}=\tau_{\pi}^{*},(b) \tau_{w, \text { sep }}^{*} \leq$ $\underline{\tau}_{w}$, and $(b)$ the policy $\tau_{\text {sep }}^{*}$ satisfies the government budget constraint (2.3).

The tax rate on profit guarantees that entrepreneurs want to choose their first best research effort. By Lemma 1, the requirement of a low enough labor income tax rate, $\tau_{w, s e p}^{*} \leq \underline{\tau}_{w}$, guarantees that both low-talent and high-talent entrepreneurs are free to choose their first best research effort. Policy $\tau_{\text {sep }}^{*}$ then implements the first best, and is feasible because it satisfies the government budget constraint.

In the model with asymmetric information, implementation of the first best depends not only upon generous profit subsidies (that boost private incentives to research to the first best level) but also upon low labor income tax rates (that give the high types enough net worth to pursue their private incentives). Thus, the balancing of the budget constraint relies on consumption taxes, and the extractive power of the consumption tax is key to implementation. 


\subsubsection{Constrained First Best}

Suppose we are at a pooling equilibrium. If $z$ is the research effort common to all entrepreneurs, aggregate consumption $c^{\text {pool }}(z)$ is

$$
c^{\text {pool }}(z)=y-i^{\text {pool }}(z)-z,
$$

where $i^{\text {pool }}(z) \equiv i(z, z)$. The government's welfare function becomes

$$
v^{\text {pool }}(z) \equiv \frac{c^{\text {pool }}(z)}{1-\beta g^{\text {pool }}(z)},
$$

where $g^{\text {pool }}(z)=g(z, z)$. Define the constrained first best allocation, $z_{\text {pool }}^{*}$, as the level of research effort that the government would like to implement if it presumes financial markets are at a pooling equilibrium, i.e.

$$
z_{\text {pool }}^{*}=\arg \max _{z \geq 0} v^{\text {pool }}(z)
$$

Then,

$$
\frac{-\left[c^{\text {pool }}\right]^{\prime}\left(z_{\text {pool }}^{*}\right)}{\bar{a} \mu^{\prime}\left(z_{\text {pool }}^{*}\right)}=\frac{\beta(\gamma-1) c^{\text {pool }}\left(z_{\text {pool }}^{*}\right)}{1-\beta g^{\text {pool }}\left(z_{\text {pool }}^{*}\right)} .
$$

Conditional on inducing a pooling equilibrium with adverse selection, the constrained first best allocation is the socially-optimal allocation. It is possible to show that, as anticipated, $z_{\text {pool }}^{*}<z_{H}^{*}$ : at a pooling equilibrium where the low types invest as much as the high types, the first best level of research effort by the high types is higher than socially optimal. ${ }^{17}$

We next turn to implementation:

Definition. Policy $\tau_{\text {pool }}^{*}$ implements the constrained first best research effort $z_{\text {pool }}^{*}$ in a pooling equilibrium with adverse selection if $(a) \tau_{\pi, \text { pool }}^{*}$ satisfies

\footnotetext{
${ }^{17}$ By definition, it must be $v\left(z_{H}^{*}, z_{L}^{*}\right)>v\left(z_{\text {pool }}^{*}, z_{\text {pool }}^{*}\right)=v^{\text {pool }}\left(z_{\text {pool }}^{*}\right)$. Then, re-write condition (4.4) as $\frac{1}{\bar{a} \mu^{\prime}\left(z_{\text {pool }}^{*}\right)}=\frac{\beta(\gamma-1) c^{\text {pool }}\left(z_{\text {pool }}^{*}\right)}{1-\beta g^{\text {pool }}\left(z_{\text {pool }}^{*}\right)}-\alpha^{\frac{2}{1-\alpha}}(\gamma-1) L$, and compare it to the expression in footnote (16). Since the RHS of the present expression is lower, the LHS must also be. Then, it must $\bar{a} \mu^{\prime}\left(z_{\text {pool }}^{*}\right)>a_{H} \mu^{\prime}\left(z_{H}^{*}\right)$, and $z_{\text {pool }}^{*}<z_{H}^{*}$.
} 


$$
1=\bar{a} \mu^{\prime}\left(z_{\text {pool }}^{*}\right) \gamma \pi\left(1-\tau_{\pi, p o o l}^{*}\right)
$$

(b) $\tau_{w, \text { pool }}^{*}>\bar{\tau}_{w}$, and $(c)$ the policy $\tau_{\text {pool }}^{*}$ satisfies the government budget constraint (2.3).

The tax rate on profit guarantees that, conditional on a pooling equilibrium realising, entrepreneurs choose the constrained first best research effort. By Lemma 1, the requirement of a high enough labor income tax rate, $\tau_{w, p o o l}^{*}>\bar{\tau}_{w}$, guarantees that a pooling equilibrium realises. Policy $\tau_{\text {pool }}^{*}$ then implements the constrained first best, and is feasible because it satisfies the government budget constraint. It is easy to show that the profit subsidy (could be a tax) needed to implement the constrained first best is lower than the subsidy needed to implement the first best, $\tau_{\pi, \text { pool }}^{*}>\tau_{\pi}^{*}{ }^{18}$

In the model with asymmetric information, Assumption 3 does not guarantee that the first best allocation is implementable independent of any restriction on consumption taxes. This allows discussion of second best allocations when the government cannot freely tax consumption. However, it also does not guarantee that the constrained first best allocation is implementable independent of any restriction on consumption taxes, which complicates the analysis of second best allocations. In order to ensure the constrained first best allocation is implementable, I make the following assumption.

Assumption 4. Given the tax rates on profit and wages required to implement the constrained first best allocation without taxing consumption, the agents' research and investment choices are consistent with a risk-free interest rate equal to zero.

It is possible to show, as we do in Appendix A, that the tax rates mentioned in Assumption 4 always exist. In other words, there always exist tax rates on profit and wages that implement the constrained first best without taxing consumption. Assumption 4 additionally ensures that such rates are consistent with a zero risk-free interest rate.

\footnotetext{
${ }^{18}$ This follow from the fact, shown in footnote (17), that $\bar{a} \mu^{\prime}\left(z_{\text {pool }}^{*}\right)>a_{H} \mu^{\prime}\left(z_{H}^{*}\right)$, together with $\bar{a} \mu^{\prime}\left(z_{\text {pool }}^{*}\right) \gamma \pi\left(1-\tau_{\pi, \text { pool }}^{*}\right)=a_{H} \mu^{\prime}\left(z_{H}^{*}\right) \gamma \pi\left(1-\tau_{\pi}^{*}\right)=1$.
} 
Because of Assumption 4, no matter how severe a restriction on consumption taxes the government faces, the constrained first best allocation is implementable. This simplifies considering second best policy in the presence of a restriction on the consumption tax, because any candidate equilibria with adverse selection other than the constrained first best cannot be optimal.

\subsubsection{Second Best Allocation}

Now we describe how optimal tax policy and the corresponding allocation varies with an exogenous restriction on the rate of consumption taxation. Suppose the consumption tax is restricted to be no greater than $\bar{\tau}_{c} \in[0, \infty)$. To find the second best tax policy, we first need to find the best implementable allocation in a separating equilibrium with no adverse selection, and then compare it to the constrained first best.

Let $\tau_{\text {sep }}^{*}$ be the consumption-tax-minimizing policy that implements the first best in a separating equilibrium with no adverse selection. Then:

$$
\tau_{c, s e p}^{*}=\frac{1}{c}\left[s-\tau_{\pi}^{*} \pi-\underline{\tau}_{w} w L\right] .
$$

If the exogenous restriction on the rate of consumption taxation allows for this policy, $\bar{\tau}_{c} \geq \tau_{c, s e p}^{*}$, the government is able to implement the first best allocation in a separating equilibrium free of adverse selection.

If $\bar{\tau}_{c}<\tau_{c, s e p}^{*}$, the government cannot implement the first best in a separating equilibrium. To illustrate the trade off involved in the identification of the best implementable separating equilibrium, consider the following experiment. Suppose the government is initially implementing the first best through tax vector $\tau_{\text {sep }}^{*}$, when the exogenous restriction on the rate of consumption taxation drops to a level $\bar{\tau}_{\pi}<\tau_{c, s e p}^{*}$. To preserve budget balance, the government must increase at least one of $\tau_{w}$ and $\tau_{\pi}$. If it only increases $\tau_{w}$, by Lemma 1, the effort threshold $z_{\text {sep }}$ shifts in, making the high types strategically constrained. Effort by the high types decreases, whereas effort by the low types stays constant. If, instead, the government increases $\tau_{w}$ slightly less, compensating with a slight increase in $\tau_{\pi}$, the inward shift in the threshold 
$z_{\text {sep }}$ is less pronounced. Effort by the high types decreases less, while effort by the low types also decreases. In any industry where the high types select $\bar{z}_{\text {sep }}$, the government faces a similar trade-off, since any increase in $\tau_{w}$ pushes $\bar{z}_{\text {sep }}$ out, further away from the social optimum. The identification of the best implementable separating equilibrium requires a balancing act between these two alternative ways to cope with a less generous consumption taxation.

Denote by $v^{\text {sep }}$ welfare at the best implementable separating equilibrium. We express this as a function of the constraint that makes it necessary to implement the second best, $\bar{\tau}_{c}$, and the exogenous spending requirement that puts additional pressure on the government budget, $s$.

Lemma 5. The function $v^{\text {sep }}\left(\bar{\tau}_{c}, s\right)$ is non-decreasing in $\bar{\tau}_{c}$, non-increasing in s. It is $v^{\text {sep }}\left(\bar{\tau}_{c}, s\right)=v\left(\tau_{H}^{*}, \tau_{L}^{*}\right)$ for $\bar{\tau}_{c} \geq \tau_{c, s e p}^{*}$.

Results in Lemma 5 are intuitive. If the exogenous limit on the consumption tax decreases or the exogenous spending requirement increases, welfare at the best implementable separating equilibrium cannot increase. This is because such a change can either not affect the trade off between profit and labor taxes, or make it more tight. In the latter case, allocations that were implementable before the change may not be implementable after. As argued above, if $\bar{\tau}_{c}>\tau_{c, \text { sep }}^{*}$, the first best is implementable in a separating equilibrium, and first best welfare is achieved.

To identify the second best, the government compares welfare at the best implementable separating equilibrium and at the constrained first best.

Proposition 6. There exists a threshold tax rate on consumption, $\tau_{c}^{\min } \in$ $\left[0, \tau_{c, \text { sep }}^{*}\right.$ ) (with $\frac{\partial \tau_{c}^{m i n}}{\partial s} \geq 0$ ) such that, if $\bar{\tau}_{c}<\tau_{c}^{\text {min }}$, the government implements a second best pooling equilibrium with adverse selection; if $\bar{\tau}_{c} \geq \tau_{c}^{\text {min }}$, the government implements a second best separating equilibrium free of adverse selection. The second best pooling equilibrium with adverse selection is equal to the constrained first best allocation.

Figure 4.1 visually describes this result. If $\bar{\tau}_{c} \geq \tau_{c, s e p}^{*}$, the government can implement the first best, and $v^{s e p}\left(\bar{\tau}_{c}, s\right)$ (the thick solid line) is higher than welfare at the constrained first best, $v^{\text {pool }}\left(z_{\text {pool }}^{*}\right)$. But suppose $\bar{\tau}_{c}$ falls below 
$\tau_{c, s e p}^{*}$, and the government insists on implementing a separating equilibrium. Because the trade off between higher profit taxes and higher labor taxes - or between lower research by the low types, and lower research by the high types (excessively high research in any industry where $\bar{z}_{\text {sep }}$ is selected) - has become more tight, $v^{\text {sep }}\left(\bar{\tau}_{c}, s\right)$ decreases. In contrast, $v^{\text {pool }}\left(z_{\text {pool }}^{*}\right)$ stays constant, because no such trade off exists at a pooling equilibrium: the government can always tax labor income to finance the profit subsidy needed to implement the constrained first best. The threshold $\tau_{c}^{m i n}$ is identified as the level of $\bar{\tau}_{c}$ where the two curves cross. If $\bar{\tau}_{c}<\tau_{c}^{\min }$, research efforts are so penalised at a separating equilibrium, that the government finds it worthwhile to allow adverse selection, in order to be able to lower the profit tax to encourage more research. (If the curves do not cross for $\bar{\tau}_{c}>0$, then $\tau_{c}^{\min }=0$, and the government always prefers a separating equilibrium). An increase in the exogenous spending requirement from $s$ to $s^{\prime}$ increases $\tau_{c}^{m i n}$ in the figure, because it shifts the function $v^{s e p}\left(\bar{\tau}_{c}, s\right)$ down to the thick dashed line. This makes the government more likely to choose an equilibrium with adverse selection.

In connection with the discussion on the effects of competition in Section 3.2, Proposition 6 hints at an interesting interaction between taxation and competition policy. If taxation policy is so constrained (by a low $\bar{\tau}_{c}$ or a high $s$ ) that the government implements a pooling equilibrium with adverse selection, this creates an environment in which only the standard Schumpeterian link between competition and innovation is present. Then, policies that favour competition, by decreasing $\pi$, decrease innovation (at least in this simple model). If, on the contrary, the government is able to implement a separating equilibrium, more competition may generate more survival of the fittest, and thus more innovation. In other words, a weakening of fiscal constraints may make both taxation policy and competition policy more effective.

\section{Conclusion}

This paper studies tax policy in a model of asymmetric information in the financing of innovation. In the model, the existence or even the threat of 


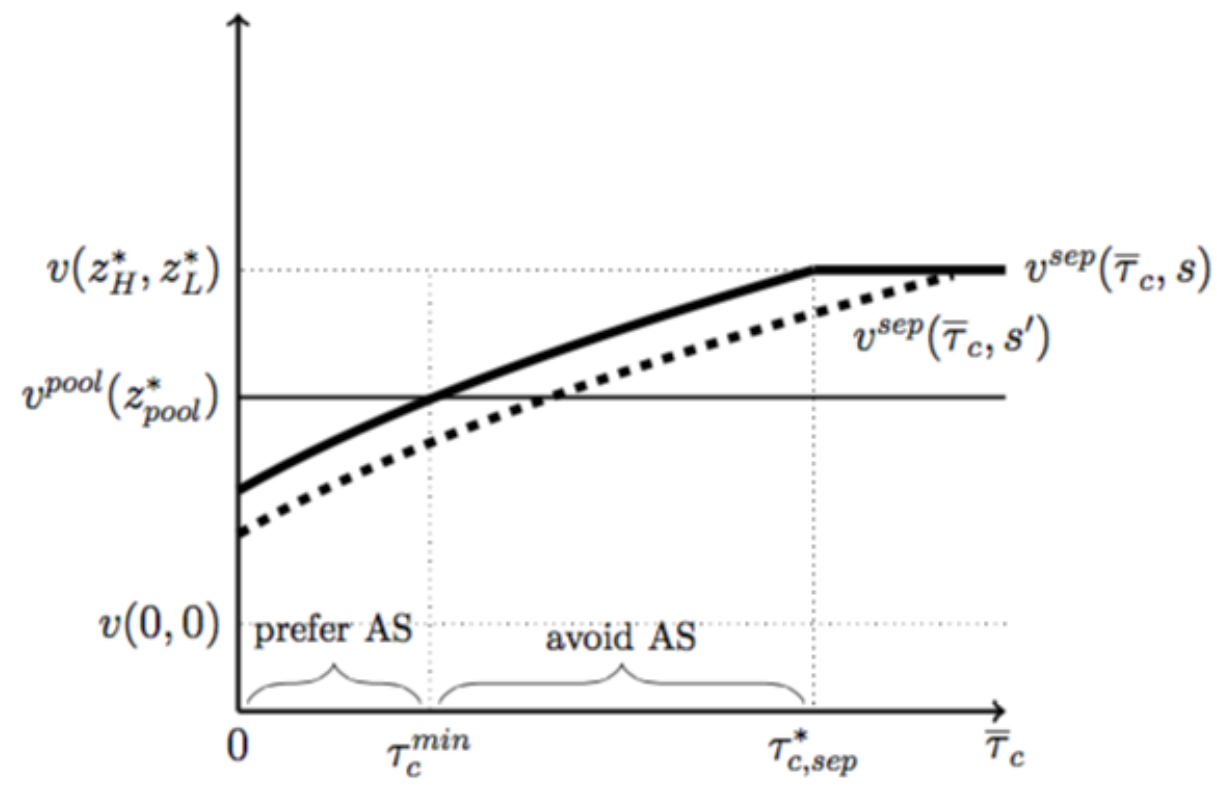

Figure 4.1: The second best allocation

adverse selection constrains the research effort of talented entrepreneurs by raising their cost of capital. A policymaker's response should be to boost net-worth and thus make talented entrepreneurs less reliant on outside credit. However, the source of tax revenue that finances the reduction in labor income taxes determines to what extent the government should follow this recommendation. Trading off profit and labor income taxes creates a tension between entrepreneurs' incentives to pursue research and their need for pledge-able income to avoid adverse selection. Meanwhile, taxing consumption allows the government to simultaneously subsidize profits and labor income without inducing any additional distortions. Consequently, if the policymaker is sufficiently constrained in his ability to tax consumption, he should not attempt to implement a "first best" allocation. The necessarily low tax on labor income would require excessively taxing profits and lowering the rate of innovation.

The modeling approach is simple and straightforward. We do not derive optimal policy as the solution to a mechanism design problem, opting in favor 
of more realistic and clearly implementable macro policies. On top of this, we consider only linear tax rates. The literature on economic inequality provides an important rationale to study non-linear taxation, but that is not the focus here.

The model's industrial organization is monopolistic. This assumption rules out studying the effects of policies when there are heterogeneously constrained firms competing with each other for market share, a process which naturally should play an important role in understanding the implications of policy for economic growth. Nonetheless, it is important to mention that even in its simple form our model is able to generate an interesting new result on the role of competition: it provides a new explanation for an inverted-U relationship between profits and innovation, which is a key result of the empirical literature on product market competition and growth that the standard Schumpeterian model cannot address (see ?). Given the pervasiveness of asymmetric information in financial markets, it would be important to understand how asymmetric information interacts with the dynamics of competition; this represents a promising avenue for future research.

Furthermore, the model is carefully constructed so that the choices across entrepreneurs (conditional on their type) and firms in different industries are identical in productivity-adjusted terms. Consequently, it cannot address how differences in financial constraints affects growth across industries. Although this is an attractive question, in order to build understanding it is important first to study the effects of asymmetric information on policy in the most straightforward environment.

Finally, a politico-economic structure that endogenizes the process through which government is motivated to pursue policy and how it finances policy reforms is outside the scope of this paper, but a prime candidate for future research. An environment where both the origins and consequences of policy design have a common root in a political process would allow us to understand why government policy would fail when faced with adverse selection in the financing of innovation, even if we understood how policy could be reformed. 


\section{A Complete Description of the Benchmark Model}

This section describes aspects of the benchmark model omitted from the main body of the paper.

\section{A.1 Industry equilibrium}

The production of the consumption good is perfectly competitive and requires a mixture of industry-specific labor $L_{i t}$ and intermediate goods $X_{i t}$ according to

$$
Y_{t} \equiv \int_{0}^{1} Y_{i t} d i, \quad Y_{i t} \equiv\left(A_{i t} L_{i t}\right)^{1-\alpha} X_{i t}^{\alpha}, \quad 0<\alpha<1
$$

Consumption good producers maximize profit taking as given the intermediate good prices $P_{i t}$ and wages $W_{i t}$ (consumption is the numeraire)

$$
\max _{X_{i t}, L_{i t}} Y_{t}-\int_{0}^{1}\left(P_{i t} X_{i t}+W_{i t} L_{i t}\right) d i
$$

which implies equilibrium expressions for the industry-specific wage and an inverse demand curve for intermediate goods

$$
\begin{aligned}
W_{i t} L_{i t} & =(1-\alpha) Y_{i t}, \\
P_{i t} & =\alpha\left(\frac{A_{i t} L_{i t}}{X_{i t}}\right)^{1-\alpha} .
\end{aligned}
$$

In equilibrium, $L_{i t}=L$ since the supply of industry-specific labor is inelastic.

An investment of $I_{i t}$ consumption goods at $t$ yields $X_{i, t+1}=I_{i t}$ intermediate goods at $t+1$. The interest rate is $1+r_{t+1}$ (for now, we consider the general case). The intermediate good is produced by a monopolist, who understands equation (A.1). At the time of production, the good's quality $A_{i, t+1}$ is predetermined. The monopolist chooses $I_{i t}$ to maximize discounted profit

$$
\Pi_{i, t+1} \equiv \frac{P_{i, t+1} X_{i, t+1}-\left(1+r_{t+1}\right) I_{i t}}{1+r_{t+1}}=\left(\frac{P_{i, t+1}}{1+r_{t+1}}-1\right) I_{i t}
$$


which in equilibrium implies (after substitution of the inverse demand curve)

$$
\frac{P_{i, t+1}}{1+r_{t+1}}=\frac{1}{\alpha}
$$

and investment and profit are linear functions of productivity $A_{i, t+1}$ :

$$
\begin{aligned}
I_{i t} & =\left(\frac{\alpha^{2}}{1+r_{t+1}}\right)^{\frac{1}{1-\alpha}} A_{i, t+1} L, \\
\prod_{i, t+1} & =(1-\alpha) \alpha^{\frac{1+\alpha}{1-\alpha}}\left(1+r_{t+1}\right)^{\frac{-1}{1-\alpha}} A_{i, t+1} L .
\end{aligned}
$$

The contribution of each industry toward the production of the consumption good is driven by the scale of production and technological change. The marginal contribution of each industry at $t$ is

$$
Y_{i t}=\left(A_{i t} L\right)^{1-\alpha}\left(I_{i, t-1}\right)^{\alpha}=\left(\frac{\alpha^{2}}{1+r_{t}}\right)^{\frac{\alpha}{1-\alpha}} A_{i t} L
$$

and the industry wage

$$
W_{i t}=\frac{(1-\alpha) Y_{i t}}{L}=(1-\alpha)\left(\frac{\alpha^{2}}{1+r_{t}}\right)^{\frac{\alpha}{1-\alpha}} A_{i t}
$$

\section{A.2 Aggregation}

The linearity of the industry-specific equations and the convenience of the notation adopted make aggregation simple. Aggregate (and average) investment and output are

$$
\begin{gathered}
I_{t}=\left(\frac{\alpha^{2}}{1+r_{t+1}}\right)^{\frac{1}{1-\alpha}} A_{t+1} L, \\
Y_{t}=\left(\frac{\alpha^{2}}{1+r_{t}}\right)^{\frac{\alpha}{1-\alpha}} A_{t} L,
\end{gathered}
$$

where $A_{t}=\int_{0}^{1} A_{i t} d i$. The average wage is

$$
W_{t}=(1-\alpha)\left(\frac{\alpha^{2}}{1+r_{t}}\right)^{\frac{\alpha}{1-\alpha}} A_{t}
$$


It is straightforward to reformulate these aggregate variables in productivityadjusted terms:

$$
\begin{aligned}
i_{t}\left(z_{\left.H, z_{L}\right)}\right. & =\frac{I_{t}}{A_{t}}=\left(\frac{\alpha^{2}}{1+r_{t+1}}\right)^{\frac{1}{1-\alpha}}\left(1+(\gamma-1) \bar{\mu}\left(z_{H,} z_{L}\right)\right) L \\
y_{t} & =\frac{Y_{t}}{A_{t}}=\left(\frac{\alpha^{2}}{1+r_{t}}\right)^{\frac{\alpha}{1-\alpha}} L, \\
w_{t} & =\frac{W_{t}}{A_{t}}=(1-\alpha)\left(\frac{\alpha^{2}}{1+r_{t}}\right)^{\frac{\alpha}{1-\alpha}},
\end{aligned}
$$

where $\bar{\mu}\left(z_{H}, z_{L}\right)$ was defined in Section 2.3. These normalised variables do not depend on $t$ once we assume a zero risk-free interest rate.

\section{A.3 Condition for a zero risk-free interest rate}

The assumption of linear preferences with a zero discount rate ensures that, if $r=0$, young agents are willing to lend (including equity to themselves) up to their entire net income, $\left(1-\tau_{w}\right) w L$. For the interest rate to be zero in equilibrium, total demand for credit (both equity and external borrowing), $i\left(z_{H}, z_{L}\right)+\bar{z}$, must be lower than $\left(1-\tau_{w}\right) w L$.

Assumption 3 requires that the minimum labor tax needed to implement the first best without taxing consumption, $\tau_{w}=\frac{1}{w L}\left[s-\tau_{\pi}^{*} \pi\right]\left(\right.$ where $\left.\tau_{\pi}^{*}<0\right)$ be small enough, so that $i\left(z_{H}^{*}, z_{L}^{*}\right)+\frac{1}{2} z_{H}^{*}+\frac{1}{2} z_{L}^{*}<\left(1-\tau_{w}\right) w L$. The assumption boils down to the requirement that $\left|\tau_{\pi}^{*}\right|$ and $s$ be not too large.

Although the minimum labor tax needed to finance $\tau_{\pi, \text { pool }}^{*}$ without taxing consumption, $\tau_{w}=\frac{1}{w L}\left[s-\tau_{\pi, \text { pool }}^{*} \pi\right]$, is lower than $\frac{1}{w L}\left[s-\tau_{\pi}^{*} \pi\right]$, Assumption 3 is not enough to ensure implementability of the constrained first best, and Assumption 4 is needed. This is for two reasons. First, implementation of the constrained first best imposes an additional lower bound on the labor tax, $\bar{\tau}_{w}$. If $\bar{\tau}_{w} \geq \frac{1}{w L}\left[s-\tau_{\pi}^{*} \pi\right]$, implementation of the constrained first best requires a higher labor tax (and lower credit supply) than implementation of the first best. Second, one cannot rule out that total credit demand is higher at the constrained first best than at the first best, i.e. $i^{\text {pool }}\left(z_{\text {pool }}^{*}\right)+z_{\text {pool }}^{*}>$ 
$i\left(z_{H}^{*}, z_{L}^{*}\right)+\frac{1}{2} z_{H}^{*}+\frac{1}{2} z_{L}^{*}$.

Finally, we show that the tax rates mentioned in Assumption 4 always exist, so that the constrained first best is always implementable. Let $\widetilde{\tau}_{w, p o o l}=\frac{1}{w L}[s-$ $\left.\tau_{\pi, \text { pool }}^{*} \pi\right]$ be the rate of labor taxation required to finance $\tau_{\pi, \text { pool }}^{*}$ without taxing consumption. There are two possible cases. If $\widetilde{\tau}_{w, p o o l}>\bar{\tau}_{w}$, then the vector $\left(\tau_{\pi, \text { pool }}^{*}, \widetilde{\tau}_{w, \text { pool }}, 0\right)^{\prime}$ implements the constrained first best (since it satisfies the definition of $\tau_{\text {pool }}^{*}$ ) without taxing consumption. If $\widetilde{\tau}_{w, \text { pool }} \leq \bar{\tau}_{w}$, then the vector $\left(\tau_{\pi, \text { pool }}^{*}, \bar{\tau}_{w}+\epsilon,-\left(\bar{\tau}_{w}+\epsilon-\widetilde{\tau}_{w, \text { pool }}\right) \frac{w L}{c}\right)^{\prime}$, with $\epsilon$ arbitrarily small, implements the constrained first best (since it satisfies the definition of $\tau_{\text {pool }}^{*}$ ) without taxing consumption (since it implies a subsidy on consumption).

\section{A.4 Discussion of Assumptions}

The model has a few assumptions that deserve discussion, namely (1) technology enters as a variable in the production of consumption goods rather than intermediate goods, and (2) labor is industry-specific yet is not an input into intermediate good production.

In most models of imperfect competition, labor is not an input in the consumption good production function. By modeling innovations as labor productivity-augmenting changes in the consumption good production function, the optimal investment decision of the monopolist becomes linear in technology. The linearity of the model substantially simplifies the aggregate and dynamic properties of the economy. For a textbook treatment of this technique, see ?.

The assumption of industry-specific labor is very important for tractability considerations. In a model with financial market imperfections, entrepreneurial net-worth is an important determinant of investment in technological research. In a common labor market wherein all entrepreneurs are born with equivalent labor endowments, entrepreneurs earn equivalent labor incomes. On the other hand, since innovation profits are linear in productivity and an innovating entrepreneur has monopoly power, the benefit to research is larger for entrepreneurs in high versus low productivity industries. Thus, entrepreneurs with low net-worth in high productivity industries should be more constrained 
than entrepreneurs with high net-worth in low productivity industries. Since net-worth is equivalent to labor income in the model, and labor income is equivalent across entrepreneurs in a common labor market, indeed entrepreneurs would be heterogeneously affected by financial market imperfections if we assumed a common labor market. To avoid this channel, which is not of first order importance to the themes of this paper and hence not worth the added complexity, we assume that the labor market for each industry is fragmented. In this way, net-worth scales with the gains from research in any given industry. One last assumption is crucial to ensure that both the financial market imperfections symmetrically affect entrepreneurs and that the model has nice convergence properties: the contribution of some fixed research effort to the probability of innovation decreases inverse-linearly with the productivity of the entrepreneur's industry. Otherwise, an entrepreneur whom did not face sufficiently steep increasing costs to research would expand his research effort until his probability of innovation approached one (at infinity), whereas he would invest a negligible share of net-worth on research, implying that the financial market imperfections would have no effect in steady state. If the increase in research costs were too steep, the entrepreneur's desired research effort would approach zero, and there would not exist a [positive] balanced growth path. 


\section{B Proofs}

We begin by establishing a few preliminary results, and we then move to the proofs of the lemmas and propositions in the main text.

\section{B.1 Preliminary results}

Theorem 1. If $\hat{z}_{H}\left(\tau_{\pi}\right) \leq\left(1-\tau_{w}\right) w$, there only exists a separating equilibrium in which $z_{J}=\hat{z}_{J}\left(\tau_{\pi}\right)$ (any combination of equity and external financing being possible).

Proof. Since the opportunity cost of equity financing is zero, the high types have enough net worth, and the minimum rate they can be offered on external financing is $\frac{1}{a_{H} \mu(z)}$, the high types would never select a research effort different from $\hat{z}_{H}\left(\tau_{\pi}\right)$. Furthermore, they would never take on external financing at a rate greater than $\frac{1}{a_{H} \mu(z)}$. This last fact implies that a pooling equilibrium does not exist. As argued in footnote 10, at any separating equilibrium, the low types must select $\hat{z}_{L}\left(\tau_{\pi}\right)$. Then, there only exists a separating equilibrium in which $z_{J}=\hat{z}_{J}\left(\tau_{\pi}\right)$. If an entrepreneur of type $J$ borrows any money at such equilibrium, this must be at a rate $\frac{1}{a_{J} \mu\left(\hat{z}_{J}\left(\tau_{\pi}\right)\right)}$. Then, the entrepreneur is indifferent as to the amount borrowed, and any combination of equity and external financing is possible.

The following results focus on the case $\hat{z}_{H}\left(\tau_{\pi}\right)>\left(1-\tau_{w}\right) w$.

Theorem 2. Let $z_{\text {sep }}$ and $\bar{z}_{\text {sep }}$ be the minimum and maximum solutions to

$$
\widetilde{n p v}^{L}(z)=n p v^{L}\left(\hat{z}_{L}\right)
$$

or, if no solutions exist, $z_{\text {sep }}=\bar{z}_{\text {sep }}=\hat{z}_{H}$. Then, for $\left(1-\tau_{w}\right) w<\hat{z}_{H}$ :

1. It is $z_{\text {sep }}>\left(1-\tau_{w}\right) w$ if $\left(1-\tau_{w}\right) w \neq \hat{z}_{L}, z_{\text {sep }}=\left(1-\tau_{w}\right) w$ if $\left(1-\tau_{w}\right) w=\hat{z}_{L}$.

2. As $\left(1-\tau_{w}\right) w$ increases from 0 to $\bar{\omega} \in\left(\hat{z}_{L}, \hat{z}_{H}\right)$, $z_{\text {sep }}$ continuously increases from a value in $\left(0, \hat{z}_{L}\right)$ to $\hat{z}_{H}$, while $\bar{z}_{\text {sep }}$ continuously decreases from a value above $\hat{z}_{H}$ to $\hat{z}_{H}$; they are both constant in $\left(1-\tau_{w}\right) w$ and equal to $\hat{z}_{H}$ for $\left(1-\tau_{w}\right) w>\bar{\omega}$. 
3. There exists $\check{z} \in\left(\hat{z}_{L}, \hat{z}_{\text {pool }}\right)$, such that $n p v^{H}\left(z_{\text {sep }}\right) \leqq n p v_{\text {pool }}^{H}\left(\hat{z}_{\text {pool }}\right) \Longleftrightarrow$ $z_{s e p} \leqq \check{z}$

4. $n p v^{H}\left(z_{\text {sep }}\right) \leqq n p v_{\text {pool }}^{H}\left(\hat{z}_{\text {pool }}\right) \Longleftrightarrow n p v^{L}\left(\hat{z}_{L}\right) \leqq n p v_{\text {pool }}^{L}\left(\hat{z}_{\text {pool }}\right)$.

Proof. Recall

$$
\begin{aligned}
\widetilde{n p v}^{L}(z) & =a_{L} \mu(z) \gamma \pi\left(1-\tau_{\pi}\right)-\frac{a_{L}}{a_{H}} z-\frac{a_{H}-a_{L}}{a_{H}}\left(1-\tau_{w}\right) w, \\
n p v^{L}\left(\hat{z}_{L}\right) & =a_{L} \mu\left(\hat{z}_{L}\right) \gamma \pi\left(1-\tau_{\pi}\right)-\hat{z}_{L},
\end{aligned}
$$

and $n p v^{L}\left(\hat{z}_{L}\right)$ is a positive number. $\widetilde{n p v}^{L}(z)$ is a concave function of $z$, which is non-positive at $z=0$, reaches a unique maximum at $z=\hat{z}_{H}$, and is negative for $z$ large enough. It also decreases linearly in $\left(1-\tau_{w}\right) w$. It is easy to see that, if $\left(1-\tau_{w}\right) w=0$, it is $\widetilde{n p v}^{L}\left(\hat{z}_{L}\right)>n p v^{L}\left(\hat{z}_{L}\right)$, implying $\widetilde{n p v}^{L}\left(\hat{z}_{H}\right)>n p v^{L}\left(\hat{z}_{L}\right)$; if $\left(1-\tau_{w}\right) w=\hat{z}_{L}$, it is $\widetilde{n p v}^{L}\left(\hat{z}_{L}\right)=n p v^{L}\left(\hat{z}_{L}\right)$, implying $\widetilde{n p v}^{L}\left(\hat{z}_{H}\right)>n p v^{L}\left(\hat{z}_{L}\right)$; and if $\left(1-\tau_{w}\right) w=\hat{z}_{H}$, it is $\widetilde{n p v}^{L}\left(\hat{z}_{H}\right)<n p v^{L}\left(\hat{z}_{L}\right)$. Then, there exists $\bar{\omega} \in$ $\left(\hat{z}_{L}, \hat{z}_{H}\right)$ such that, if $\left(1-\tau_{w}\right) w<\bar{\omega}$, equation (B.1) admits two solutions, $0<z_{\text {sep }}<\hat{z}_{H}<\bar{z}_{\text {sep }}<\infty$; if $\left(1-\tau_{w}\right) w=\bar{\omega}$, it admits only one solution, $z_{\text {sep }}=\bar{z}_{\text {sep }}=\hat{z}_{H}$; and if $\left(1-\tau_{w}\right) w>\bar{\omega}$, it admits no solutions (which, by definition, still implies $\left.z_{\text {sep }}=\bar{z}_{\text {sep }}=\hat{z}_{H}\right)$. Furthermore, $z_{\text {sep }}$ is smaller than $\hat{z}_{L}$ for $\left(1-\tau_{w}\right) w=0$, increases with $\left(1-\tau_{w}\right) w$ and goes to $\hat{z}_{H}$ as $\left(1-\tau_{w}\right) w$ goes to $\bar{\omega} ; \bar{z}_{\text {sep }}$ is bigger than $\hat{z}_{H}$ for $\left(1-\tau_{w}\right) w=0$, decreases with $\left(1-\tau_{w}\right) w$ and goes to $\hat{z}_{H}$ as $\left(1-\tau_{w}\right) w$ goes to $\bar{\omega}$. Point 2 follows. Next, note that $\widetilde{n p v}^{L}\left(\left(1-\tau_{w}\right) w\right)=n p v^{L}\left(\left(1-\tau_{w}\right) w\right)$. Then, $\widetilde{n p v}^{L}\left(\left(1-\tau_{w}\right) w\right)<n p v^{L}\left(\hat{z}_{L}\right)$ if $\left(1-\tau_{w}\right) w \neq \hat{z}_{L}, \widetilde{n p v}^{L}\left(\left(1-\tau_{w}\right) w\right)=n p v^{L}\left(\hat{z}_{L}\right)$ if $\left(1-\tau_{w}\right) w=\hat{z}_{L}$, Point 1 follows from the fact that $\left(1-\tau_{w}\right) w<\hat{z}_{H}$, and $\widetilde{n p v}^{L}(z)$ reaches a maximum at $\hat{z}_{H}$. Next, the expression

$$
n p v^{H}\left(z_{\text {sep }}\right)-n p v_{\text {pool }}^{H}\left(\hat{z}_{\text {pool }}\right)
$$

is continuously increasing in $z_{\text {sep }}$. To see this, start from $\widetilde{n p v}^{L}\left(z_{\text {sep }}\right)=n p v^{L}\left(\hat{z}_{L}\right)$. After multiplying both sides by $\frac{a_{H}}{a_{L}}$ and re-arranging, this can written as

$$
a_{H} \mu\left(z_{\text {sep }}\right) \gamma \pi\left(1-\tau_{\pi}\right)-z_{\text {sep }}=a_{H} \mu\left(\hat{z}_{L}\right) \gamma \pi\left(1-\tau_{\pi}\right)-\frac{a_{H}}{a_{L}} \hat{z}_{L}+\frac{a_{H}-a_{L}}{a_{L}}\left(1-\tau_{w}\right) w
$$


where the LHS is equal to $n p v^{H}\left(z_{s e p}\right)$. Then, (B.2) can be written as

$$
\begin{aligned}
a_{H} \mu\left(\hat{z}_{L}\right) \gamma \pi\left(1-\tau_{\pi}\right) & -\frac{a_{H}}{a_{L}} \hat{z}_{L}+\frac{a_{H}-a_{L}}{a_{L}}\left(1-\tau_{w}\right) w- \\
& {\left[a_{H} \mu\left(\hat{z}_{\text {pool }}\right) \gamma \pi\left(1-\tau_{\pi}\right)-\frac{a_{H}}{\bar{a}} \hat{z}_{\text {pool }}+\frac{a_{H}-\bar{a}}{\bar{a}}\left(1-\tau_{w}\right) w\right], }
\end{aligned}
$$

which is increasing in $\left(1-\tau_{w}\right) w$ and thus $z_{\text {sep }}$. Next, (B.2) is negative for $z_{\text {sep }}=\hat{z}_{L}$, positive for $z_{\text {sep }}=\hat{z}_{\text {pool }}$. To see the former, note that, by point 1 , $z_{\text {sep }}=\hat{z}_{L}$ implies $\left(1-\tau_{w}\right) w=z_{\text {sep }}$. Then

$n p v_{\text {pool }}^{H}\left(\hat{z}_{\text {pool }}\right)>n p v_{\text {pool }}^{H}\left(z_{\text {sep }}\right)=n p v_{\text {pool }}^{H}\left(\left(1-\tau_{w}\right) w\right)=n p v^{H}\left(\left(1-\tau_{w}\right) w\right)=n p v^{H}\left(z_{\text {sep }}\right)$.

To see the latter, note that $n p v_{\text {pool }}^{H}\left(\hat{z}_{\text {pool }}\right)<n p v^{H}\left(\hat{z}_{\text {pool }}\right)=n p v^{H}\left(z_{\text {sep }}\right)$. Point 3 follows. Finally, suppose $n p v_{\text {pool }}^{H}\left(\hat{z}_{\text {pool }}\right) \leqq n p v^{H}\left(z_{\text {sep }}\right)$. After replacing $n p v^{H}\left(z_{\text {sep }}\right)$ from equation (B.3) and multiplying both sides by $\frac{a_{L}}{a_{H}}$, this can be written as

$$
\begin{aligned}
& a_{L} \mu\left(\hat{z}_{\text {pool }}\right) \gamma \pi\left(1-\tau_{\pi}\right)-\frac{a_{L}}{\bar{a}}\left[\hat{z}_{\text {pool }}-\left(1-\tau_{w}\right) w\right]-\left(1-\tau_{w}\right) w \leqq \\
& a_{L} \mu\left(\hat{z}_{L}\right) \gamma \pi\left(1-\tau_{\pi}\right)-\hat{z}_{L},
\end{aligned}
$$

which is the same as $n p v_{\text {pool }}^{L}\left(\hat{z}_{\text {pool }}\right) \leqq n p v^{L}\left(\hat{z}_{L}\right)$. Point 4 follows.

Theorem 3. If and only if $z_{\text {sep }} \geq \check{z}$ (where $\check{z}$ was defined in Theorem 2) the following is a PBE:

(a) Lenders believe that those who contribute $\left(1-\tau_{w}\right) w$ in equity and invest $z \in\left(\left(1-\tau_{w}\right) w, z_{s e p}\right]$ are high types; those who contribute $\left(1-\tau_{w}\right) w$ in equity and invest $z>z_{\text {sep }}$ have equal probability of being high types or low types; and everybody else are low types. They then offer rate $\frac{1}{a_{H} \mu(z)}$ to the first group, rate $\frac{1}{\bar{a} \mu(z)}$ to the second, and rate $\frac{1}{a_{L} \mu(z)}$ to the third. Low types invest $\hat{z}_{L}$ (any combination of equity and external financing being possible). High types invest $z_{\text {sep }}$ (contributing $\left(1-\tau_{w}\right) w$ in equity).

If and only if $z_{\text {sep }} \leq \check{z}$, the following is a PBE:

(b) Lenders have the same beliefs and strategy as in (a). Both high and low types invest $\hat{z}_{\text {pool }}$ (contributing $\left(1-\tau_{w}\right) w$ in equity). 
Proof. Let $\succsim^{J}$ represent type $J$ 's preferences, and $b_{J} \geq 0$ be the amount of borrowing that $J$ could have contributed in equity, but did not. Then, $b_{J} \in\left[0, \min \left(\left(1-\tau_{w}\right) w, z_{J}\right)\right]$, and the pair $\left(z_{J}, b_{J}\right)$ uniquely identifies J's action.

Consider $(a)$ first. Facts AI.-AIII.i. below prove that $(a)$ is a PBE if $z_{s e p} \geq \check{z}$. Fact AIII.ii. proves that it is not a PBE if $z_{\text {sep }}<\check{z}$. AI. For every action that borrowers could play, the lenders' action is optimal given their beliefs. AII. If $z_{\text {sep }} \geq \check{z}$, for actions that borrowers play in equilibrium, the lenders' beliefs are correct (since $\left.\hat{z}_{L}<\left(1-\tau_{w}\right) w<z_{\text {sep }}\right)$. AIII.i. If $z_{\text {sep }} \geq \check{z}$, borrowers do not have a profitable deviation. Type $H$. Their equilibrium action, $\left(z_{\text {sep }}, 0\right)$, gives payoff $n p v^{H}\left(z_{\text {sep }}\right)$. We want to show that $\left(z_{\text {sep }}, 0\right) \succsim^{H}$ $\left(z_{H}, b_{H}\right)$ for any $\left(z_{H}, b_{H}\right) \neq\left(z_{\text {sep }}, 0\right)$. We proceed in two steps. First, we show that $\left(z_{\text {sep }}, 0\right) \succsim^{H}\left(z_{H}, 0\right)$ for any $z_{H} \neq z_{\text {sep }}$. To see this, note that, if $z_{H} \in\left[0, z_{\text {sep }}\right),\left(z_{H}, 0\right)$ gives payoff $n p v^{H}\left(z_{H}\right)$; and $z_{H}<z_{\text {sep }} \leq \hat{z}_{H}$ implies $n p v^{H}\left(z_{H}\right)<n p v^{H}\left(z_{\text {sep }}\right)$. If $z_{H}>z_{\text {sep }},\left(z_{H}, 0\right)$ gives payoff $n p v_{\text {pool }}^{H}\left(z_{H}\right) \leq$ $n p v_{\text {pool }}^{H}\left(\hat{z}_{\text {pool }}\right)$, and $z_{\text {sep }} \geq \check{z}$ implies $n p v_{\text {pool }}^{H}\left(\hat{z}_{\text {pool }}\right) \leq n p v^{H}\left(z_{\text {sep }}\right)$. Second, we show that $\left(z_{H}, 0\right) \succsim^{H}\left(z_{H}, b_{H}\right)$ for any $z_{H}>0$ and feasible $b_{H}>0$. This follows from the fact that the total cost of funding is higher in $\left(z_{H}, b_{H}\right)$ than in $\left(z_{H}, 0\right)$ : $\left(\frac{a_{H}}{a_{L}}-1\right) b_{H}$ higher if $z_{H} \in\left(0,\left(1-\tau_{w}\right) w\right] ;\left(\frac{a_{H}}{a_{L}}-1\right)\left(b_{H}+z_{H}-\left(1-\tau_{w}\right) w\right)$ higher if $z_{H} \in\left(\left(1-\tau_{w}\right) w, z_{s e p}\right]$; and $\left(\frac{a_{H}}{a_{L}}-1\right) b_{H}+\left(\frac{a_{H}}{a_{L}}-\frac{a_{H}}{\bar{a}}\right)\left(z_{H}-\left(1-\tau_{w}\right) w\right)$ higher if $z_{H}>z_{\text {sep }}$. Type $L$. Their equilibrium action, $\left(\hat{z}_{L}, b\right)$ (with $b \in\left[0, \hat{z}_{L}\right]$ ), gives payoff $n p v^{L}\left(\hat{z}_{L}\right)$. We want to show that $\left(\hat{z}_{L}, b\right) \succsim^{H}\left(z_{L}, b_{L}\right)$ for any $\left(z_{L}, b_{L}\right) \neq\left(\hat{z}_{L}, b\right)$. We proceed in two steps. First, we show that $\left(\hat{z}_{L}, b\right) \succsim^{H}$ $\left(z_{L}, b_{L}\right)$ for any $\left(z_{L}, b_{L}\right)$ such that either $z_{L} \leq\left(1-\tau_{w}\right) w$, or $b_{L}>0$. To see this, note that any such $\left(z_{L}, b_{L}\right)$ gives payoff $n p v^{L}\left(z_{L}\right)$, and $n p v^{L}\left(z_{L}\right) \leq n p v^{L}\left(\hat{z}_{L}\right)$. Second, we show that $\left(\hat{z}_{L}, b\right) \succsim^{H}\left(z_{L}, 0\right)$ for any $\left(z_{L}, 0\right)$ such that $z_{L}>(1-$ $\left.\tau_{w}\right) w$. To see this, note that, if $z_{L} \in\left(\left(1-\tau_{w}\right) w, z_{s e p}\right],\left(z_{L}, 0\right)$ gives payoff $\widetilde{n p v}^{L}\left(z_{L}\right)$, and, by definition of $z_{\text {sep }}, \widetilde{n p v}^{L}\left(z_{L}\right)<n p v^{L}\left(\hat{z}_{L}\right)$. If $z_{L}>z_{\text {sep }},\left(z_{L}, 0\right)$ gives payoff $n p v_{\text {pool }}^{L}\left(z_{L}\right) \leq n p v_{\text {pool }}^{L}\left(\hat{z}_{\text {pool }}\right)$. But $z_{\text {sep }} \geq \check{z}$ implies $n p v_{\text {pool }}^{L}\left(\hat{z}_{\text {pool }}\right) \leq$ $n p v^{L}\left(\hat{z}_{L}\right)$. AIII.ii. If $z_{\text {sep }}<\check{z}$, some borrowers have a profitable deviation. For example, it is $n p v_{\text {pool }}^{H}\left(\hat{z}_{\text {pool }}\right)>n p v^{H}\left(z_{\text {sep }}\right)$, implying that $H$ have a profitable deviation to $\left(\hat{z}_{\text {pool }}, 0\right)$.

Next, consider $(b)$. Facts BI.-BIII.i. below prove that $(b)$ is a PBE if 
$z_{s e p} \leq \check{z}$. Fact BIII.ii. proves that it is not a PBE if $z_{s e p}>\check{z}$. BI. For every action that borrowers could play, the lenders' action is optimal given their beliefs. BII. If $z_{\text {sep }} \leq \check{z}$, for actions that borrowers play in equilibrium, lenders' beliefs are correct (since $z_{\text {sep }}<\hat{z}_{\text {pool }}$ ). BIII.i. If $z_{\text {sep }} \leq \check{z}$, borrowers do not have a profitable deviation. Type $H$. Their equilibrium action, $\left(\hat{z}_{\text {pool }}, 0\right)$, gives payoff $n p v_{\text {pool }}^{H}\left(\hat{z}_{\text {pool }}\right)$. We want to show that $\left(\hat{z}_{\text {pool }}, 0\right) \succsim^{L}\left(z_{H}, b_{H}\right)$ for any $\left(z_{H}, b_{H}\right) \neq\left(\hat{z}_{\text {pool }}, 0\right)$. We proceed in two steps. First, we show that $\left(\hat{z}_{\text {pool }}, 0\right) \succsim^{H}$ $\left(z_{H}, 0\right)$ for any $z_{H} \neq \hat{z}_{\text {pool }}$. To see this, note that, if $z_{H} \in\left[0, z_{\text {sep }}\right],\left(z_{H}, 0\right)$ gives payoff $n p v^{H}\left(z_{H}\right)$, and $z_{H} \leq z_{\text {sep }}<\hat{z}_{H}$ implies $n p v^{H}\left(z_{H}\right) \leq n p v^{H}\left(z_{s e p}\right)$; furthermore, $z_{\text {sep }} \leq \check{z}$ implies $n p v^{H}\left(z_{\text {sep }}\right) \leq n p v_{\text {pool }}^{H}\left(\hat{z}_{\text {pool }}\right)$. If $z_{H}>z_{\text {sep }},\left(z_{H}, 0\right)$ gives $n p v_{\text {pool }}^{H}\left(z_{H}\right)$, and $n p v_{\text {pool }}^{H}\left(z_{H}\right) \leq n p v_{\text {pool }}^{H}\left(\hat{z}_{\text {pool }}\right)$. Second, by fact AIII.i., it is $\left(z_{H}, 0\right) \succsim^{H}\left(z_{H}, b_{H}\right)$ for any $z_{H}>0$ and feasible $b_{H}>0$. Type $L$. Their equilibrium action, $\left(\hat{z}_{\text {pool }}, 0\right)$, gives payoff $n p v_{\text {pool }}^{L}\left(\hat{z}_{\text {pool }}\right)$. We want to show that $\left(\hat{z}_{\text {pool }}, 0\right) \succsim^{L}\left(z_{L}, b_{L}\right)$ for any $\left(z_{L}, b_{L}\right) \neq\left(\hat{z}_{\text {pool }}, 0\right)$. We show this in two steps. First, we show that $\left(\hat{z}_{\text {pool }}, 0\right) \succsim^{L}\left(z_{L}, b_{L}\right)$ for any $\left(z_{L}, b_{L}\right)$ such that either $z_{L} \leq\left(1-\tau_{w}\right) w$, or $b_{L}>0$. To see this, note that any such $\left(z_{L}, b_{L}\right)$ gives payoff $n p v^{L}\left(z_{L}\right)$. But $n p v^{L}\left(z_{L}\right) \leq n p v^{L}\left(\hat{z}_{L}\right)$, and $z_{\text {sep }} \leq \check{z}$ implies $n p v^{L}\left(\hat{z}_{L}\right) \leq n p v_{\text {pool }}^{L}\left(\hat{z}_{\text {pool }}\right)$. Second, we show that $\left(\hat{z}_{\text {pool }}, 0\right) \succsim^{L}\left(z_{L}, 0\right)$ for any $\left(z_{L}, 0\right)$ such that $z_{L}>\left(1-\tau_{w}\right) w$. To see this, note that, if $z_{L} \in\left(\left(1-\tau_{w}\right) w, z_{s e p}\right]$, $\left(z_{L}, 0\right)$ gives payoff $\widetilde{n p v}^{L}\left(z_{L}\right)$, and, by definition of $z_{s e p}, \widetilde{n p v}^{L}\left(z_{L}\right) \leq n p v^{L}\left(\hat{z}_{L}\right)$; furthermore, $z_{\text {sep }} \leq \check{z}$ implies $n p v^{L}\left(\hat{z}_{L}\right) \leq n p v_{\text {pool }}^{L}\left(\hat{z}_{\text {pool }}\right)$. If $z_{L}>z_{\text {sep }},\left(z_{L}, 0\right)$ gives payoff $n p v_{\text {pool }}^{L}\left(z_{L}\right)$, and $n p v_{\text {pool }}^{L}\left(z_{L}\right) \leq n p v_{\text {pool }}^{L}\left(\hat{z}_{\text {pool }}\right)$. BIII.ii. If $z_{\text {sep }}>\check{z}$, some borrowers have a profitable deviation. For example, it is $n p v_{\text {pool }}^{H}\left(\hat{z}_{\text {pool }}\right)<$ $n p v^{H}\left(z_{s e p}\right)$, implying that $H$ have a profitable deviation to $\left(z_{s e p}, 0\right)$.

\section{B.2 Proofs}

Lemma 1. There exists $\underline{\tau}_{w}$ and $\bar{\tau}_{w}$, with $-\infty<\underline{\tau}_{w}<\bar{\tau}_{w}<1$ such that:

- If $\tau_{w} \leq \underline{\tau}_{w}$, the high types are unconstrained: a separating equilibrium realises, where $z_{\text {sep }}=\hat{z}_{H}\left(\tau_{\pi}\right)$.

- If $\tau_{w} \in\left(\underline{\tau}_{w}, \bar{\tau}_{w}\right]$, the high types are strategically constrained: a separating equilibrium realises, where $z_{\text {sep }} \in\left(\hat{z}_{L}\left(\tau_{\pi}\right), \hat{z}_{H}\left(\tau_{\pi}\right)\right)$. 
- If $\tau_{w}>\bar{\tau}_{w}$, the high types are constrained: a pooling equilibrium realises. If $\tau_{w} \in\left(\underline{\tau}_{w}, \bar{\tau}_{w}\right], z_{\text {sep }}$ is decreasing in $\tau_{w}$, increasing in $\tau_{\pi}$.

Proof. Points 2 and 3 in Theorem 2 imply that there exists $\underline{\omega}<\bar{\omega}$ such that $z_{\text {sep }}=\check{z}$ iff $\left(1-\tau_{w}\right) w=\underline{\omega}$. Let $\underline{\tau}_{w} \equiv \arg _{\tau}\left[\left(1-\tau_{w}\right) w=\bar{\omega}\right]$ and $\bar{\tau}_{w} \equiv \arg _{\tau}[(1-$ $\left.\left.\tau_{w}\right) w=\underline{\omega}\right]$. By Theorem 2, if $\tau_{w} \leq \underline{\tau}_{w}$, it is $z_{s e p}=\hat{z}_{H}>\check{z}$; if $\tau_{w} \in\left(\underline{\tau}_{w}, \bar{\tau}_{w}\right]$, it is $z_{\text {sep }} \in\left[\check{z}, \hat{z}_{H}\right)$; and if $\tau_{w}>\bar{\tau}_{w}$ it is $z_{\text {sep }}<\check{z}$. The first part of the Lemma then follows from Theorem 3. Next, suppose $\tau_{w} \in\left(\underline{\tau}_{w}, \bar{\tau}_{w}\right]$. Theorem 2 implies that $z_{\text {sep }}$ is decreasing in $\tau_{w}$. Differentiating both sides of $\widetilde{n p v}^{L}\left(z_{\text {sep }} \mid \tau\right)=n p v^{L}\left(\hat{z}_{L} \mid \tau\right)$ with respect to $\tau_{\pi}$ :

$$
\begin{gathered}
a_{L} \mu^{\prime}\left(z_{\text {sep }}\right) \frac{\partial z_{\text {sep }}}{\partial \tau_{\pi}} \gamma \pi\left(1-\tau_{\pi}\right)-a_{L} \mu\left(z_{\text {sep }}\right) \gamma \pi-\frac{a_{L}}{a_{H}} \frac{\partial z_{\text {sep }}}{\partial \tau_{\pi}}= \\
a_{L} \mu^{\prime}\left(\hat{z}_{L}\right) \frac{\partial \hat{z}_{L}}{\partial \tau_{\pi}} \gamma \pi\left(1-\tau_{\pi}\right)-a_{L} \mu\left(\hat{z}_{L}\right) \gamma \pi-\frac{\partial \hat{z}_{L}}{\partial \tau_{\pi}} \\
\frac{\partial z_{\text {sep }}}{\partial \tau_{\pi}}=\frac{a_{L} \mu\left(z_{\text {sep }}\right) \gamma \pi-a_{L} \mu\left(\hat{z}_{L}\right) \gamma \pi}{\frac{a_{L}}{a_{H}}\left[a_{H} \mu^{\prime}\left(z_{\text {sep }}\right) \gamma \pi\left(1-\tau_{\pi}\right)-1\right]}>0,
\end{gathered}
$$

where we used $a_{L} \mu^{\prime}\left(\hat{z}_{L}\right) \gamma \pi\left(1-\tau_{\pi}\right)=1$ to simplify.

Proposition 2. Lowering the tax on profit always boosts research effort by the low types, and by the high types at a separating equilibrium in which they are unconstrained $\left(z_{\text {sep }}=\hat{z}_{H}\left(\tau_{\pi}\right)\right)$, or at a pooling equilibrium. At a separating equilibrium in which the high types are strategically constrained $\left(z_{\text {sep }}<\hat{z}_{H}\left(\tau_{\pi}\right)\right)$, lowering the labor income tax boosts their research effort, and so does increasing the tax on profit.

Proof. Since the low types choose $\hat{z}_{L}\left(\tau_{\pi}\right)$ at a separating equilibrium and $\hat{z}_{\text {pool }}\left(\tau_{\pi}\right)$ at a pooling equilibrium, and the high types choose $\hat{z}_{H}\left(\tau_{\pi}\right)$ at a separating equilibrium in which they are unconstrained, and $\hat{z}_{\text {pool }}\left(\tau_{\pi}\right)$ at a pooling equilibrium, the first part of the proposition follows from equations (2.1) and (3.2). The second part follows from Lemma 1.

Lemma 5. The function $v^{\text {sep }}\left(\bar{\tau}_{c}, s\right)$ is non-decreasing in $\bar{\tau}_{c}$, non-increasing in s. It is $v^{\text {sep }}\left(\bar{\tau}_{c}, s\right)=v\left(\tau_{H}^{*}, \tau_{L}^{*}\right)$ for $\bar{\tau}_{c} \geq \tau_{c, s e p}^{*}$. 
Proof. Suppose the exogenous constraint on the consumption tax drops from $\bar{\tau}_{c}$ to $\bar{\tau}_{c}^{\prime}$ (ceteris paribus), and the government enforces a separating equilibrium both before and after the change. Denote by $\tau$ and $\tau^{\prime}$ taxes before and after the change. It is

$$
\begin{aligned}
\tau_{\pi} \pi+\tau_{w} w L+\tau_{c} c & =s \\
\tau_{\pi}^{\prime} \pi+\tau_{w}^{\prime} w L+\tau_{c}^{\prime} c & =s .
\end{aligned}
$$

If $\tau_{c}^{\prime} \geq \tau_{c}$, welfare must be unchanged. This follows from the fact that, since $\tau_{c} \leq \tau_{c}^{\prime} \leq \bar{\tau}_{c}^{\prime}<\bar{\tau}_{c}$, both $\tau$ and $\tau^{\prime}$ are feasible both before and after the change. If $\tau_{c}^{\prime}<\tau_{c}$, welfare cannot be higher after the change. This is because, since $\tau_{c}^{\prime}<\tau_{c} \leq \bar{\tau}_{c}, \tau^{\prime}$ was feasible (but not chosen) before the change.

Similarly, suppose the exogenous spending requirement increases from $s$ to $s^{\prime}$ (ceteris paribus), and the government enforces a separating equilibrium both before and after the change. It is

$$
\begin{aligned}
& \tau_{\pi} \pi+\tau_{w} w L+\tau_{c} c=s \\
& \tau_{\pi}^{\prime} \pi+\tau_{w}^{\prime} w L+\tau_{c}^{\prime} c=s^{\prime} .
\end{aligned}
$$

If $\tau_{\pi}^{\prime} \pi+\tau_{w}^{\prime} w L \leq \tau_{\pi} \pi+\tau_{w} w L$, welfare must be unchanged. This follows from the fact that both the old and the new allocation are feasible both before and after the change. To see this, note that $\tau^{\prime}$ must be such that $\tau_{c}^{\prime} c-\tau_{c} c=\tau_{\pi} \pi+$ $\tau_{w} w L-\tau_{\pi}^{\prime} \pi-\tau_{w}^{\prime} w L+s^{\prime}-s$. Then, the new allocation was feasible before the change by selecting $\hat{\tau}_{c}<\tau_{c}^{\prime} \leq \bar{\tau}_{c}$ such that $\hat{\tau}_{c} c-\tau_{c} c=\tau_{\pi} \pi+\tau_{w} w L-\tau_{\pi}^{\prime} \pi-\tau_{w}^{\prime} w L$, $\hat{\tau}_{w}=\tau_{w}^{\prime}$, and $\hat{\tau}_{\pi}=\tau_{\pi}^{\prime}$; and the old allocation is feasible after the change by selecting $\widetilde{\tau}_{c} \leq \tau_{c}^{\prime} \leq \bar{\tau}_{c}$ such that $\widetilde{\tau}_{c} c-\tau_{c} c=s^{\prime}-s, \widetilde{\tau}_{w}=\tau_{w}$ and $\widetilde{\tau}_{\pi}=\tau_{\pi}$. So, the new allocation cannot be optimal. If $\tau_{\pi}^{\prime} \pi+\tau_{w}^{\prime} w L>\tau_{\pi} \pi+\tau_{w} w L$, welfare cannot be higher after the change. This is because the new allocation was feasible (but not chosen) before the change, by selecting $\hat{\tau}_{c}<\tau_{c} \leq \bar{\tau}_{c}$ such that $\hat{\tau}_{c} c-\tau_{c} c=\tau_{\pi} \pi+\tau_{w} w L-\tau_{\pi}^{\prime} \pi-\tau_{w}^{\prime} w L, \hat{\tau}_{w}=\tau_{w}^{\prime}$ and $\hat{\tau}_{\pi}=\tau_{\pi}^{\prime}$. Finally, that $v^{\text {sep }}\left(\bar{\tau}_{c}, s\right)=v\left(z_{H}^{*}, z_{L}^{*}\right)$ for $\bar{\tau}_{c} \geq \tau_{c, s e p}^{*}$ follows from the fact that the first best is implementable in this case. 
Proposition 6. There exists a threshold tax rate on consumption, $\tau_{c}^{\min } \in$ $\left[0, \tau_{c, s e p}^{*}\right.$ ) (with $\frac{\partial \tau_{c}^{m i n}}{\partial s} \geq 0$ ) such that, if $\bar{\tau}_{c}<\tau_{c}^{\text {min }}$, the government implements a second best pooling equilibrium with adverse selection; if $\bar{\tau}_{c} \geq \tau_{c}^{\min }$, the government implements a second best separating equilibrium free of adverse selection. The second best pooling equilibrium with adverse selection is equal to the constrained first best allocation.

Proof. If $\bar{\tau}_{c} \geq \tau_{c, s e p}^{*}$, vector $\tau_{\text {sep }}^{*}$ is feasible, and the best implementable separating equilibrium must then coincide with the first best. Then, $v_{s e p}\left(\bar{\tau}_{c}, s\right)=$ $v\left(z_{H}^{*}, z_{L}^{*}\right)>v\left(z_{\text {pool }}^{*}, z_{\text {pool }}^{*}\right)=v^{\text {pool }}\left(z_{\text {pool }}^{*}\right)$. Since $v_{\text {sep }}\left(\bar{\tau}_{c}, s\right)$ is non-decreasing in $\bar{\tau}_{c}$ but $v^{\text {pool }}\left(z_{\text {pool }}^{*}\right)$ is constant, there are two cases: it is either $v_{s e p}\left(\bar{\tau}_{c}, s\right)>$ $v^{\text {pool }}\left(z_{\text {pool }}^{*}\right)$ for $\bar{\tau}_{c} \in\left[0, \tau_{c, \text { sep }}^{*}\right)$, or $v_{\text {sep }}\left(\bar{\tau}_{c}, s\right) \geq v^{\text {pool }}\left(z_{\text {pool }}^{*}\right)$ for $\bar{\tau}_{c} \in\left[\tau, \tau_{c, \text { sep }}^{*}\right)$, $v_{\text {sep }}\left(\bar{\tau}_{c}, s\right)<v\left(z_{\text {pool }}^{*}\right)$ for $\bar{\tau}_{c} \in[0, \tau)$. In the second case, $\tau$ is non-decreasing in $s$, since $v_{\text {sep }}\left(\bar{\tau}_{c}, s\right)$ is non increasing while $v\left(z_{\text {pool }}^{*}\right)$ is constant. Let $\tau_{c}^{\min }=0$ in the first case, $\tau_{c}^{\min }=\tau$ in the second case. Then, $\bar{\tau}_{c} \geq \tau_{c}^{\min }$ guarantees that $v_{\text {sep }}\left(\bar{\tau}_{c}, s\right) \geq v^{\text {pool }}\left(z_{\text {pool }}^{*}\right), \bar{\tau}_{c}<\tau_{c}^{\text {min }}$ guarantees that $v_{\text {sep }}\left(\bar{\tau}_{c}, s\right)<v^{\text {pool }}\left(z_{\text {pool }}^{*}\right)$. The proposition then follows. 